\title{
Fiscal Policy with Heterogeneous Agents and Incomplete Markets
}

\author{
Jonathan Heathcote* \\ Stockholm School of Economics
}

July 28, 1999

\begin{abstract}
I undertake a quantitative investigation into the short run effects of changes in the timing of taxes for a model economy in which heterogeneous households trade only one asset and face a borrowing constraint. This asset market structure implies that the consumption of low wealth households is sensitive to tax changes. The main finding of the paper is that when the wealth distribution in the model resembles that in the United States, market incompleteness accounts for large immediate aggregate consumption increases following tax cuts, and large consumption falls following tax increases. When taxes are lump-sum, for example, a dollar change in tax revenue is associated with a 15 cent change in aggregate consumption, compared to a response of roughly one third this size when markets are complete but households are finitely-lived. I find the response to tax changes to be larger if the interest rate is constant rather than determined endogenously, and smaller if taxes are proportional rather than lump-sum.
\end{abstract}

${ }^{*}$ I am greatly indebted to my advisor Andrew Atkeson for his continuing help and support. I also thank Lee Ohanian, Jose-Victor Rios-Rull, Richard Rogerson, Randall Wright, Nicholas Souleles, Stephen Zeldes, Morten Ravn, Narayana Kocherlakota, Anton Braun, Paul Klein, and Kjetil Storesletten. 


\section{Introduction}

The Ricardian insight, revisited by Barro (1974), is that with dynastic households, lump-sum taxes, and perfect capital markets, changes in the timing of taxes should not affect households' optimal consumption decisions. Thus the Ricardian theory predicts an equivalence in terms of prices and allocations between any time paths for taxes that imply the same total present value for tax revenue. In constrast to this theoretical result, a large amount of empirical work suggests that the timing of taxes does matter. For example, Bernheim (1987) argues that "virtually all [aggregate consumption function] studies indicate that every dollar of deficits stimulates between $\$ 0.20$ and $\$ 0.50$ of current consumer spending". In the hope of reconciling the apparent gap between the Ricardian view and the empirical evidence, various authors have explored quantitative theoretical models in which one or more of the conditions for Ricardian equivalence are not satisfied.

Ricardian equivalence may fail if a tax change reduces the tax burden on the current generation at the expense of future generations. However, even the extreme assumption of zero inter-generational altruism does not appear capable of rationalizing the magnitude of observed deviations from Ricardian equivalence. For example, assuming taxes rise to stabilize debt after a one year tax cut, Poterba and Summers (1987) find a marginal propensity to consume (MPC) of about 0.06. Hubbard and Judd (1986) examine five-year deficits repaid over periods of either 10 or 20 years and find MPCs of between 0.03 and 0.05 . The explanation for these small numbers is straightforward. Households do treat the fraction of a tax cut that will be paid for by the next generation as an addition to net wealth. However, households want to smooth any increase in consumption over the remainder of their lifetimes, and average life expectancy is long relative to the duration of the tax cuts considered.

A second obvious candidate for generating real effects from tax changes is distortionary taxation, since changes in the timing of distorting taxes affect the optimal inter-temporal allocation of labor effort and investment (see, for example, Auerbach and Kotlikoff 1987, Trostel 1993, Braun 1994, and McGrattan 1994). Distortionary tax cuts imply short run decreases in consumption when the tax cut is on capital income (due to the increased incentive to save), and increases in consumption when it is on labor income (due to the increased incentive to supply labor which raises output). For general income tax changes, the magnitude of the consumption response appears to be small. For example, in his central case (an income tax cut with a five year duration), Trostel finds that on impact consumption falls by 2.5 cents per dollar change in tax revenue.

The third key assumption underlying the Ricardian result is that asset markets 
are complete. This paper re-examines an old idea that the presence of liquidity constraints might be able to explain large short run real effects from temporary tax changes. I describe a dynamic general equilibrium model in which infinitelylived heterogeneous households receive idiosyncratic shocks to labor efficiency which cannot be insured. Households can reduce the sensitivity of consumption to income changes by accumulating precautionary holdings of a single asset. However, if household asset holdings ever reach zero then further dissaving is prohibited; households face a "no-borrowing" constraint. Since households differ in their productivity histories, the model generates an endogenous cross-sectional distribution of asset holdings.

The government in the model economy finances constant government spending by issuing debt and levying taxes. Taxes are stochastic, so households face risk at the aggregate as well as at the idiosyncratic level. The intuition for why tax changes have short run real effects is as follows. Households that are unfortunate enough to have both very low asset holdings and low current labor income would like to borrow against future labor income to increase consumption (since they expect higher labor income in the future) but are prevented from doing so by the no-borrowing constraint. If the government cuts taxes, the borrowing constraint for such households is effectively loosened; they can now increase consumption by the extent to which the tax cut raises disposable income. This story suggests that tax changes will have larger effects on aggregate variables the greater the fraction of wealth-poor households. I therefore calibrate the model economy so that the distribution of wealth generated endogenously resembles that in the United States.

I focus primarily on lump-sum tax systems, since in a world of lump sum taxes and infinitely-lived households, any real effects from temporary tax changes will be attributable to the asset market structure. Thus there is a sense in which examining lump sum tax shocks is a natural way to assess the importance of asset market incompleteness as a propagation mechanism. I also investigate changes in the timing of taxes under a proportional tax system, in both complete and incomplete asset market environments. The goal here is to gauge the relative importance of distortionary taxation versus market incompleteness in terms of generating deviations from Ricardian equivalence. To solve numerically for equilibrium allocations in the model economies I use the method recently developed by Krusell and Smith (1998). This method permits a good approximation to the true solution for economies with large numbers of heterogeneous agents and aggregate uncertainty.

The main finding of the paper is that capital market imperfections can give 
rise to quantitatively important departures from Ricardian equivalence. ${ }^{1}$ For example, when taxation is lump-sum and the asset holding distribution resembles that in the United States, a 15.2 percent fall in the tax level that is expected to decay over 10 quarters is associated with an immediate increase in aggregate consumption of 15.0 cents per dollar fall in tax revenue. Following a similar tax cut under a proportional tax system, aggregate consumption initially falls by 1.3 cents per dollar fall in revenue when asset markets are complete, whereas it rises by 8.3 cents when idiosyncratic risk is uninsurable and borrowing is prohibited. These findings suggest that the asset market structure may be more important than the tax system for understanding the short run real effects of temporary tax changes. $^{2}$

The rest of the paper is organized as follows. In the next section I review the empirical evidence on the response of aggregate consumption to tax changes, and the evidence on the importance of liquidity constraints at the household level. Section 3 contains a description of the model economies, along with a discussion of the solution algorithm and the choices for parameter values. In section 4 , a combination of impulse responses and simulations are used to explore the conditions under which temporary tax changes have large real effects. Section 5 concludes.

\section{Review of the Literature}

\subsection{Evidence on the response of consumption to tax changes}

There is a large and rather inconclusive literature that tests for Ricardian equivalence (RE) by estimating consumption functions or Euler equations on aggregate time series (see, for example, the surveys in Bernheim 1987 and Seater 1993). There are a variety of econometric problems which might explain why tests for $\mathrm{RE}$ using aggregate time series do not produce sharp results. One such is the problem of endogeneity. Cardia (1997) illustrates how just looking at the coef-

\footnotetext{
${ }^{1}$ Hubbard and Judd (1986) were the first to demonstrate the potential quantitative importance of borrowing constraints for the short run effects of lump sum tax changes. See also Altig and Davis (1989) and Daniel (1993). Ricardian equivalence fails in Feldstein (1988) due to the impossibility of borrowing from the next generation if you are unlucky in old age.

${ }^{2}$ The long run implications of debt accumulation in my economy are the same as those in Aiyagari and McGrattan (1997), who find that increasing the steady state level of debt crowds out aggregate capital, reducing per capita consumption. The welfare cost of this reduction in the average level of household consumption is offset by a reduction in the average volaility of household consumption, since a higher real interest rate makes assets less costly to hold and therefore more effective in smoothing individual consumption. Woodford (1990) examines similar questions in a more stylized model.
} 
ficient on the current budget deficit in an estimated consumption function (in which both output and the budget deficit are treated as independent variables) might not tell us much about whether we should reject $\mathrm{RE}$ if output responds endogenously to current tax changes. A second potential problem is that if current tax changes imply expected future government expenditure changes, then consumption might respond even if $\mathrm{RE}$ is true. As a third example, even if $\mathrm{RE}$ is false, consumption might only respond to unanticipated tax changes; this is a central implication of the permanent income / life cycle hypothesis (PILCH) model.

Given these difficulties, several authors have looked at various interesting natural experiments in which households saw large and reasonably well-understood changes in their disposable income. This work provides evidence that consumption does in fact respond significantly to tax changes, even if they are fully predictable.

Various studies of the 1968 surtax and the 1975 rebate find quite large changes in aggregate consumption from these explicitly temporary tax changes. For example, Modigliani and Steindal (1977) use some large scale econometric models and estimate a marginal propensity to consume over two quarters out of the 1975 rebate of between 0.3 and 0.58 . Blinder (1981) examines both tax changes using a model based on the permanent income hypothesis and estimates a MPC of 0.16 over a quarter. Poterba (1988), using an Euler equation-based estimation, reports a MPC of between 0.13 and 0.27 within a month. ${ }^{3}$

Wilcox (1989) finds large effects on consumption from the sequence of increases in social security benefits since 1965, even though these increases were always announced at least six weeks in advance. A dollar increase in benefits increases durables consumption by $\$ 0.85$ and non-durables consumption by $\$ 0.45$ within a month of the benefit changes taking effect. In panel data, Souleles (1997) finds the MPC out of predictable income tax refunds to be between 0.35 and 0.6 within a quarter. Finally, Shapiro and Slemrod (1995) report that 43 percent of survey respondents planned to save most of the extra disposable income they would get from the 1992 reduction in the standard rate of with-holding for income taxes.

This apparent sensitivity of U.S. consumption to predictable changes in taxes or transfers is often attributed to the presence of liquidity constraints. The aim of

\footnotetext{
${ }^{3}$ Poterba also finds that consumption did not appear to respond significantly to the passage of five large tax bills (including the 1968 and 1975 changes), even though it did respond when these tax changes were eventually implemented. While this is difficult to reconcile with standard versions of the PILCH model (and with the Ricardian proposition), aggregate consumption may respond to predictable tax changes if some.households are borrowing constrained.
} 
this paper is to investigate this story within a quantitative model. It is therefore important to ask what other evidence (in addition to the response of consumption to tax changes) supports the view that borrowing constraints affect a large fraction of the population.

\subsection{Evidence of the importance of borrowing constraints}

Work on panel data indicates that some households in the U.S. do face liquidity constraints. Moreover, there appears to be a high correlation between the households that are liquidity constrained and those that have very little wealth. Zeldes (1989) works with the P.S.I.D. and identifies the wealth-poorest and richest households in the sample. He rejects a permanent income hypothesis-based Euler equation for the poor, estimates a positive missing multiplier (suggesting they face a binding borrowing constraint), and finds that they exhibit excess consumption growth. Further cross-sectional evidence consistent with the presence of borrowing constraints is that households with low asset holdings appear to consume too little and have too little debt (see Hayashi 1985, and Cox and Jappelli 1993). ${ }^{4}$

Using data from the 1983 Survey of Consumer Finance, Jappelli (1990) finds that 12.5 percent of households report having requests for credit rejected, while a further 6.5 percent do not apply because they expected credit to refused. Thus, according to this measure, 19 percent of the U.S. population was liquidity constrained on at least one date in the year or two prior to the survey. Jappelli also finds that 74.1 percent of those households whose net worth is less than 15 percent of their disposable income are liquidity constrained (compared to 8.3 percent of those with greater net worth), suggesting that wealth-poor households are much more susceptible to finding themselves in the position of wishing to borrow but being unable to find credit. At the same time, 6.7 percent of the population both has net wealth greater than 15 percent of disposable income and reports being recently liquidity constrained. This phenomenon may arise either because the desired loan exceeds net worth, or because these households' assets are very illiquid and credit markets that would allow borrowing against such assets are imperfect.

Although the no-borrowing constraint in the model of this paper is not derived endogenously, it is possible to think of many explanations for the evidence that lenders are reluctant to make consumption loans to households with very low tangible wealth. For example, the provisions of bankruptcy law and moral hazard

\footnotetext{
${ }^{4}$ Souleles (1997) finds that on receipt of tax refunds, the nondurable consumption of those with low asset holdings rises much more than that of the rich.
} 
issues relating to future labor income may be important. Whatever the correct explanation, because both the model and the empirical evidence imply a close connection between the characteristics of having low wealth and being unable to borrow, it is important to know how many wealth-poor households there are in the United States. Diaz-Gimenez, Quadrini and Rios-Rull (1997) report that the poorest 40 percent of households hold only 1.35 percent of total wealth, that approximately 3.4 percent of households have zero wealth, and that another 3.5 percent have negative wealth (suggesting that a small fraction of households have been able to take out uncollateralized loans). Overall, these numbers suggest that a large fraction of the population may be at or near to their borrowing limit. ${ }^{5}$

\section{The Model}

The benchmark model is based upon the economies described in Aiyagari (1994) and Aiyagari and McGrattan (1998). A large (measure 1) number of households are ex ante identical and infinitely lived. They supply labor inelastically and maximize their expected discounted utility from consumption. In aggregate, household savings decisions determine the evolution of the aggregate capital stock, which in turn determines aggregate output and the return to saving. I now describe several respects in which the economy differs from a standard neoclassical growth model.

First, because the goal of the paper is to assess the potential importance of liquidity constraints, I assume that households face idiosyncratic labor productivity shocks, and that markets which in principle could allow complete insurance against this risk do not exist. Instead there is a single risk-free savings instrument which enables households to partially self-insure by accumulating precautionary asset holdings. An important assumption is that asset holdings cannot fall below zero; no borrowing is permitted. Given this market structure, a household with positive wealth responds to a fall in household income by temporarily dissaving. This means that households which have drawn a high proportion of low values for labor productivity in the recent past tend to have lower asset holdings in equilibrium than households which have typically enjoyed high productivity. The no-borrowing constraint is important because it limits the ability of low-wealth households to smooth consumption in the face of falls in their disposable income.

\footnotetext{
${ }^{5}$ Weicher (1997(b)) investigates the position of households with negative net worth in some detail. He finds that these households tend to have higher incomes and more assets than other poor households (even if they also have more liabilities). He reports that "typically, these households could achieve a positive wealth position by dedicating about 15 percent of one year's income to paying off debts". In 1992 only 11.8 percent of those households with negative net worth (or 0.57 percent of the total population) had net worth of less than $-\$ 10,000$.
} 
The second respect in which the economy differs from the simplest growth model is that there is a government which finances constant government spending by issuing one period debt and levying taxes. Contrary to the assumption in Aiyagari and McGrattan (1998), the tax level is stochastic, meaning that households face risk at the aggregate as well as at the idiosyncratic level. The combination of idiosyncratic and aggregate risk means that in equilibrium the economy exhibits both cross-sectional heterogeneity in income and wealth, and at the same time inter-temporal variation in the shape of these distributions. From the households' perspective, debt and capital are perfect substitutes since the one period return to both is risk free, and there are no transaction costs. An equilibrium condition is that aggregate asset holdings at each date must equal the sum of the capital stock and the stock of outstanding government debt.

The response of aggregate consumption to tax changes is likely to depend on the distribution of wealth in the model economy, and in particular on the fraction of households close to the no-borrowing constraint. To ensure that on average the distribution of asset holdings generated endogenously by the model resembles that observed in the United States, I introduce uninsurable idiosyncratic discount factor shocks, as in Krusell and Smith (1998). Introducing persistent idiosyncratic preference shocks increases the degree of wealth concentration that the model generates, since other things being equal, (temporarily) more patient households will save more than less patient households.

\subsection{Benchmark economy}

\section{Idiosyncratic risk}

Each infinitely-lived household supplies $\bar{n}$ labor hours per period. Household $i$ 's productivity at date $t$ is denoted by $e_{i t}$ and takes one of two possible values, $e_{i t} \in E=\left\{e_{l}, e_{h}\right\} .^{6}$

Preferences are given by

$$
E_{0} \sum_{t=0}^{\infty} u\left(c_{i t}\right) \theta_{i t}
$$

\footnotetext{
${ }^{6}$ It is straightforward to introduce exogenous, constant, labor-augmenting technological progress in this framework. Equilibrium aggregate capital, debt, output and consumption will now inherit the same long run growth rate as labor productivity. To solve this economy, it is convenient to express all variables (except the discount factor and factor prices) relative to trend labor productivity, so that the transformed variables are stationary. The transformed economy then looks much like the economy described in the text, with the exception that variables dated $t+1$ are divided by the gross constant exogenous growth rate. In results not reported, I find that introducing long-run growth does not substantially alter the short-run effects of temporary tax changes.
} 
where

$$
u\left(c_{i}\right)=\frac{c_{i}^{1-\gamma}}{1-\gamma}
$$

Here $c_{i t}$ is consumption of household $i$ at date $t$, and $\gamma>0$ is the coefficient of relative risk aversion. $\theta_{i t}$ expresses period utility at date $t+1$ in terms of period utility at date 0 and follows the following law of motion.

$$
\begin{gathered}
\theta_{i 0}=1, \quad \theta_{i t+1}=\beta_{i t} \theta_{i t} \\
\beta_{i t} \in \mathcal{B}=\left\{\beta_{l}, \beta_{h}\right\} .
\end{gathered}
$$

The subjective discount factor $\beta_{i t}$ defines household $i$ 's period utility at date $t+1$ in terms of period utility at date $t$, and is known at the start of period $t$. If $\beta_{i t}=\beta_{h}$, the household is (temporarily) of the patient type. If $\beta_{i t}=\beta_{l}$, it is impatient. Both productivity and the discount factor are assumed to be i.i.d. across agents and to evolve independently of each other and of the tax level according to first-order Markov processes. The $2 \times 2$ transition probability matrices for productivity and patience are denoted $\pi_{e}$ and $\pi_{\beta}$ respectively.

Let $a_{i t-1} \in \mathcal{A}=\mathrm{R}_{+}$denote household $i$ 's asset holdings at the start of period $t$, corresponding to a savings decision taken at $t-1$. Let $s_{i t}=\left(e_{i t}, \beta_{i t}, a_{i t-1}\right)$ denote household $i$ 's individual state at date $t$, where $s_{i t} \in S=E \times \mathcal{B} \times \mathcal{A}$.

\section{Aggregate risk}

By virtue of the law of large numbers, the only source of aggregate uncertainty in the model is the stochastic process for the economy-wide tax level. This means that the aggregate state of the economy at date $t$ can be described by the date 0 distribution of individual states across agents, the date 0 level of debt, the date 0 tax level, and the history of the tax level up to and including date $t$. I call this object the history at date $t$, and denote it $h^{t}$. The set of all possible histories up to date $t$ is denoted $H^{t}$. Let $\rho\left(h^{t}\right)$ denote the date 0 probability that the history up to date $t$ will be $h^{t}$.

The real return to supplying one unit of effective labor at $t$ is given by $w\left(h^{t-1}\right)$. The return at $t$ to one unit of the asset purchased at $t-1$ is $1+r\left(h^{t-1}\right)$. The tax level at $t$ is given by $\tau\left(h^{t}\right)$ and takes one of two possible values, $\tau\left(h^{t}\right) \in \tau=$ $\left\{\tau_{l}, \tau_{h}\right\}$. When taxation is lump-sum, the budget constraint of household $i$ at $h^{t}$ is therefore given by

$$
c_{i t}+a_{i t}=\left(1+r\left(h^{t-1}\right)\right) a_{i t-1}+w\left(h^{t-1}\right) e_{i t} \bar{n}-\tau\left(h^{t}\right) .
$$


The distribution of individual states across agents at date $t$ conditional on history $h^{t-1}$ is described by $\psi_{t}\left(\cdot ; h^{t-1}\right)$, a probability measure defined on $\mathcal{S}$, the Borel subsets of $S$. Note that the distribution of individual states across agents at $t$ is independent of the tax level at $t$.

\section{Government}

Real government spending is constant and equal to $G$. Government debt issued at date $t$ is denoted $B\left(h^{t}\right)$ and pays a certain one period return. Since the population size is normalized to 1 , aggregate tax revenue when taxation is lumpsum is simply $\tau\left(h^{t}\right)$. Thus the government budget constraint is

$$
B\left(h^{t}\right)+\tau\left(h^{t}\right)=\left(1+r\left(h^{t-1}\right)\right) B\left(h^{t-1}\right)+G .
$$

The tax level follows a Markov process with transition probabilities that depend on the current tax level and the amount of government debt issued in the period. Let the transition function $\pi_{\tau}\left(j \mid \tau\left(h^{t}\right), B\left(h^{t}\right)\right)$ give the probability that $\tau\left(h^{t+1}\right)=j$, conditional on $\tau\left(h^{t}\right)$ and $B\left(h^{t}\right)$, for all $h^{t+1}$ compatible with $h^{t}$. I discuss the law of motion for taxes in more detail in the next section.

\section{Production}

Aggregate output at $t, Y\left(h^{t}\right)$, is produced according to a Cobb-Douglas technology from aggregate capital at date $t, K\left(h^{t-1}\right)$, and aggregate labor supply, $N\left(h^{t}\right)$.

$$
Y\left(h^{t}\right)=K\left(h^{t-1}\right)^{\alpha} N\left(h^{t}\right)^{1-\alpha},
$$

where $\alpha \in[0,1]$.

The law of large numbers implies that aggregate effective labor supply is constant across dates and states. The low value for productivity, $e_{l}$, is such that, given choices for $\pi_{e}$ and $\frac{e_{h}}{e_{l}}$, aggregate effective labor supply is equal to household labor supply:

$$
N\left(h^{t}\right)=\int e_{i t} \bar{n} d \psi_{t}\left(\cdot ; h^{t-1}\right)=\bar{n} .
$$

Output can be transformed into consumption, government spending, and future capital according to

$$
C\left(h^{t}\right)+G+K\left(h^{t}\right)=Y\left(h^{t}\right)+(1-\delta) K\left(h^{t-1}\right),
$$

where $\delta \in[0,1]$ is the rate of depreciation.

Product and factor markets are assumed to be competitive. The absence of aggregate productivity shocks implies a certain one period real return to saving in the form of capital. Since the real one period return to debt is also known in advance (the government guarantees it), in equilibrium the two assets must 
pay the same real return. This is why it is not necessary to specify the division between capital and bonds in an individual's portfolio.

\section{The households' problem}

Households take as given sequences $\left\{r\left(h^{t}\right)\right\},\left\{w\left(h^{t}\right)\right\}$ and $\left\{\tau\left(h^{t}\right)\right\}$ which specify prices and taxes at every date and state. They choose stochastic processes for savings (and thus implicitly consumption) to maximize expected utility subject to their budget constraints and non-negativity constraints on consumption and savings.

I define an equilibrium for this economy in an appendix.

\subsection{The process for taxes}

The observation that the effects of current tax changes cannot be studied independently of the future tax changes that they imply is at the heart of the Ricardian equivalence proposition. However, even if government spending is held constant, recognizing that current and future taxes are not independent is not typically sufficient for predicting the response of an economy to a tax change. The reason is simply that many different paths for taxes are consistent with a stationary debt to GDP ratio.

The approach taken in this paper is to impose bounds on the level of debt issued by the government in the period, $B \in \mathcal{D}=\left[B_{l}, B_{h}\right]$, and to ensure that the tax transition function $\pi_{\tau}$ is such that if initial debt lies within $\mathcal{D}$, then future debt always remains within $\mathcal{D}$. This is implemented by ensuring that debt is always falling at the high tax level and always rising at the low tax level, and by specifying transition probabilities such that for values of $B$ close to $B_{h}$ the probability of the high tax is always 1 , while for $B$ close to $B_{l}$ it is always 0 .

More specifically, the tax level transition probabilities are given by

\begin{tabular}{c|ccc} 
& $B \leq \underline{B}$ & $\underline{B}<B<\bar{B}$ & $B \geq \bar{B}$ \\
\hline$\pi_{\tau}\left(\tau_{h} \mid \tau_{h}, B\right)$ & 0 & {$\left[\frac{B-\underline{B}}{\bar{B}-\underline{B}}\right]^{\lambda}$} & 1 \\
$\pi_{\tau}\left(\tau_{l} \mid \tau_{l}, B\right)$ & 1 & {$\left[\frac{\bar{B}-B}{\bar{B}-\underline{B}}\right]^{\lambda}$} & 0
\end{tabular}

where $\underline{B}$ and $\bar{B}$ are simple functions of $B_{h}$ and $B_{l}$ described below.

One feature of this specification is that the expected duration of a tax cut is decreasing in the indebtedness of the government, while the expected duration of a tax increase is increasing. A second feature is that the probability of a tax cut starting from the high tax level is equal to the probability of a tax increase 
starting from the low tax level, provided that $B-\underline{B}$ in the high tax regime is equal to $\bar{B}-B$ in the low tax regime. The parameter $\lambda$ controls the persistence of tax levels. Reducing $\lambda$ reduces the probability of a change in tax levels, conditional on a particular value for $B$. Given the form of the transition probability function, I now describe sufficient conditions on $\tau_{l}, \tau_{h}, \underline{B}$ and $\bar{B}$ for government debt to remain within the set $\mathcal{D}$.

The amount of debt the government needs to issue is increasing in current aggregate debt and decreasing in the tax level and current aggregate capital (since more capital implies lower interest payments on outstanding debt). Let $\mathcal{K}=\left[K_{l}, K_{h}\right]$ denote a set such that in equilibrium aggregate capital always lies in this set. Sufficient conditions for the upper bound on debt $B_{h}$ not to be violated are

$$
\tau_{h} \geq\left(1+r\left(K_{l}\right)\right) B_{h}+G-B_{h}
$$

and

$$
\bar{B} \leq \frac{B_{h}+\tau_{l}-G}{1+r\left(K_{l}\right)} .
$$

The first condition says that conditional on the tax level being high, debt is decreasing $\forall B \in \mathcal{D}$ and $\forall K \in \mathcal{K}$. The second condition says that for all levels of inherited debt consistent with a low current tax level (i.e. $\forall B<\bar{B}$ ), new debt issued does not exceed $B_{h}$.

Similarly, sufficient conditions for the lower bound on debt $B_{l}$ not to be violated are

$$
\tau_{l} \leq\left(1+r\left(K_{h}\right)\right) B_{l}+G-B_{l}
$$

and

$$
\underline{B} \geq \frac{B_{l}+\tau_{h}-G}{1+r\left(K_{h}\right)} .
$$

The parameterization section describes how I assign values to $B_{h}, B_{l}, \tau_{h}, \tau_{l}$ and $\lambda$, while ensuring that 3.1 and 3.3 are satisfied. Given these choices, $\underline{B}$ and $\bar{B}$ are set so that 3.2 and 3.4 are equalities.

\subsection{A law of motion for capital}

It is known to be difficult to solve for an equilibrium in economies with heterogeneous agents, incomplete markets, and aggregate uncertainty. I therefore adopt the strategy proposed by Krusell and Smith $(1998)^{7}$. This procedure is described in detail by Krusell and Smith and in Rios-Rull (1997), so here I only sketch how

\footnotetext{
${ }^{7}$ Den Haan (1997) proposes a similar algorithm. Other papers to implement the Krusell and Smith approach include Storesletten et. al. (1998) and Castaneda et. al. (1998).
} 
I apply the method in the context of this model. The line of attack is as follows. First, assume that when they solve their problems households use only an appropriate subset of the information about the aggregate state of the economy contained in the history $h^{t}$. Next, compute the solution for a world inhabited by these imperfectly rational households. Finally, argue that in this world whether a household uses all the information in $h^{t}$ or just the chosen subset makes essentially no difference to its behavior.

For the model economy described above, I assume that instead of using all of the information contained in $h^{t}$, households instead only use information contained in $Z_{t}=\left(K_{t-1}, B_{t-1}, \tau_{t}\right)$. In the recursive version of the revised household problem, described in an appendix, the history of the economy is summarized by $Z$, and households take as given a law of motion for aggregate capital of the form $K=G(Z)$. The solution is a decision rule of the form $a^{\prime}(s, Z)$. How to compute $a^{\prime}(s, Z)$ when $G(Z)$ is taken as given is described in an appendix.

It is important to note that the only possible error that households make when they solve the revised problem as opposed to the "true" one described earlier is that they may forecast future aggregate capital with error. Thus, in evaluating the cost of using a limited information set (and a linear forecasting rule) it is important to examine the magnitude of these forecasting errors and the implied errors in forecasting future factor prices.

For the model of this paper, the differences between actual future capital and forecasted future capital turn out to be small and on the order of those encountered by Krusell and Smith. Figure 9 contains histograms showing the 1 period and 100 period forecast errors for aggregate capital and for the real interest rate across a 10,000 period simulation of the lump-sum tax economy under the baseline parameterization. The cumulative forecasting error for capital 25 years hence is rarely more than one percentage point of the initial capital stock. Forecasting errors for the real interest rate (the marginal product of capital minus the depreciation rate) are slightly larger. A second measure of the accuracy of the forecasting rule is given by the $R^{2}$ implied when the forecasting rule is used to fit a long sample of simulated data. For the parameterization described below the $R^{2}$ is 0.99957 , suggesting a high degree of accuracy.

Since decision rules should be continuous with respect to predicted values for future capital, I argue that improving forecasting accuracy would not lead to large changes in individual decision rules or the aggregate behavior of the economy. If this claim is correct, then the Krusell and Smith computational technique is appropriate for this particular model economy.

Why is it that higher moments of the wealth distribution do not seem to be very important for forecasting future aggregate capital? The intuition is similar to 
that given in Krusell and Smith. Firstly, household savings rules are close to linear in wealth. This can be seen from figure 10 which shows savings decision rules as a function of household wealth for each combination of household productivity, the household discount factor, and the aggregate tax level. ${ }^{8}$ The graphs illustrate that the marginal propensity to save out of wealth is close to one for most values for wealth. Thus redistributing wealth between agents with moderate or greater wealth will have little effect on aggregate savings.

It is true that the marginal propensity to save can be much lower at very low levels of wealth. For example, at zero wealth, low productivity and the high tax level, the propensity to save out of wealth is zero. In principle therefore, wealth redistributions between very poor households and richer households could significantly change total savings. There are two reasons why this is not an important problem in practice. Firstly, the importance of the savings behavior of a given group is proportional to the wealth the group holds, and households with low savings propensities account for a small fraction of aggregate wealth. Secondly, information contained in the other variables contained in the forecasting rule to a certain extent substitutes for more detailed information about the shape of the wealth distribution. For example, the correlation in a simulation between the fraction of households with less than $2 \%$ of mean assets and the level of debt is -0.72 , while the correlation between the same fraction and aggregate capital is 0.87 (see table 3 ).

\subsection{Parameterization}

The model period is one quarter. All parameter values used are reported in quarterly terms in table 1 . The parameters relating to production are all taken from Aiyagari and McGrattan (1998). Capital's share in the Cobb-Douglas production function $\alpha$ is set equal to 0.3 and the depreciation rate is set to reflect an annual value of 0.075 . To calibrate the idiosyncratic productivity shocks Aiyagari and McGrattan (1998) examine a stochastic process of the form

$$
\ln e^{\prime}=\rho \ln e+\sigma\left(1-\rho^{2}\right) \varepsilon^{\prime} \quad \varepsilon \sim N(0,1) .
$$

They set $\rho=0.6$ and $\sigma=0.3$ after considering a range of estimates based on panel data. In their paper the period length is one year. I choose the two values

\footnotetext{
${ }^{8}$ In figure 10, aggregate capital and debt are set to their average equilibrium levels of 8.78 and 2.35 respectively. Mean household wealth in equilibrium is simply the sum of aggregate capital and aggregate debt. To magnify the non-linearities in decision rules close to the borrowing constraint, the decision rules in figures 10 and 11 are plotted only for low values for household wealth.
} 
for productivity and the transition probabilities to match these values for $\rho$ and $\sigma$ with a symmetric two state process in a quarterly model. The implied expected duration of both states is 4.17 years.

The risk aversion parameter $\gamma$ is set to 1 implying logarithmic utility. This leaves four remaining preference parameters that may be chosen independently: the two values for the discount factor and two probabilities of switching between them. I choose these four parameters so that when the model economy is simulated, on average it reproduces certain features of the wealth distribution recently observed in the United States.

The four statistics from United States data that this part of the calibration procedure is designed to match are: (i) the asset holding Gini co-efficient, (ii) the total fraction of aggregate wealth held by the second, third and fourth poorest deciles of the population, (iii) the fraction of aggregate wealth held by the richest decile of the population, and (iv) the capital to output ratio. The first of these criteria ensures realistic overall wealth concentration, while the second and third are more specifically aimed at matching the tails of the empirical wealth distribution. ${ }^{9}$ The fourth criterion is designed to ensure a plausible value for the average real interest rate. The target value for this statistic will also determine the total quantity of assets available for consumption smoothing - recall that in the model this quantity corresponds to the sum of the capital stock and the stock of government debt.

Using data from the 1992 Survey of Consumer Finances, Diaz-Gimenez, Quadrini and Rios-Rull (1997) report a wealth-Gini of 0.78. The second, third and fourth deciles of the distribution combined hold 1.9 percent of total wealth, while the top decile holds 66.1 percent. Adding up fixed private capital and the stock of durables owned by consumers, Aiyagari and McGrattan (1998) report a capital to annual output ratio of 2.5. Given the choices for capital's share and the depreciation rate, this implies an average annual real interest rate of 4.5 percent, a reasonable compromise for an economy in which stocks and bonds pay the same rate of return.

For a 10,000 period simulation of the calibrated model economy, the average Gini coefficient is 0.78 , the second, third and fourth deciles of the wealth distribution hold 2.2 percent of total wealth on average, the top decile holds 66.6 percent of total wealth on average, and the average capital to output ratio is 2.5 . The parameter values reported in table 1 imply that at any point in time three quarters of the population are in the impatient state, and that the expected durations of

\footnotetext{
${ }^{9} \mathrm{I}$ do not directly target the wealth holdings of the poorest decile of households since in the data 3.4 percent of households have negative net worth while in the model asset holdings must be non-negative.
} 
the impatient and patient states are 450 and 150 years respectively.

It is interesting to examine the extent to which the success of the model in reproducing the empirical wealth distribution is due to the introduction of taste shocks. I therefore solve the same model in the absence of taste shocks. Averaging across a long simulation, the wealth Gini for this economy is only 0.37, implying that a large fraction of the wealth concentration seen in the benchmark model is attributable to the taste shocks. The table below provides a more detailed comparison between the wealth distribution observed in the data, and those implied by the benchmark model and the variation on the benchmark model that does not have taste shocks.

Asset holding distributions

\begin{tabular}{cccc}
\hline & DATA & \multicolumn{2}{c}{ MODELS } \\
& & \multicolumn{2}{c}{ (averages over 10,000 periods) } \\
\hline & U.S. (92) & Benchmark & Single $\beta$ \\
\hline Gini & 0.78 & 0.78 & 0.37 \\
$99-100 \%$ & 29.6 & 18.7 & 3.3 \\
$90-100 \%$ & 66.1 & 66.6 & 23.6 \\
$80-100 \%$ & 79.5 & 84.5 & 40.6 \\
$10-40 \%$ & 1.9 & 2.2 & 14.7 \\
$0-40 \%$ & 1.4 & 2.2 & 15.7 \\
$\%$ with $\leq 0$ assets & 6.9 & 6.6 & 0.0 \\
$K / Y$ & 2.5 & 2.5 & 2.5
\end{tabular}

It is also interesting to compare the amount of wealth and income mobility implied by the model with the degree of mobility observed in the U.S., even though this is not something that the parameterization is designed to match. Tables 4 and 5 compare wealth and income mobility between 1984 and 1989 in the P.S.I.D. (as reported by Diaz-Gimenez, Quadrini and Rios-Rull) with mobility over a five year period in a simulation of the model. Overall, the amount of movement within the wealth distribution in the model is close to that observed empirically: 44.2 percent of households changed wealth quintiles between the two dates in the data, while 49.0 percent did so in the model. The model also reproduces the fact that there is greater mobility between income quintiles than between wealth quintiles: 47.8 percent of households changed income quintiles between the two dates in the data, while 61.3 percent did so in the model. However, relative to the data, the model predicts too much persistence in the wealth and income orderings at the top ends of the distributions, and too little lower down.

The consumption behavior of households with both low wealth and low income is likely to be most sensitive to the presence of the borrowing constraint and thus to tax changes. Diaz Gimenez, Quadrini and Rios Rull report that in the 
US the poorest 40 percent of households by wealth account for 21.5 percent of total earnings and 19.5 percent of total pre tax income. In my economy I find that in a typical cross sectional distribution the corresponding figures are 36.0 percent and 30.3 percent. Since the model abstracts from potentially important permanent differences in productivity and life-cycle considerations, it is not clear that comparing these numbers is very informative. Nonetheless, since wealthpoor households in the model have more income than in the data, it would seem unlikely that the specified income process biases the model towards exaggerating the importance of the borrowing constraint or the effects of tax changes.

All other model parameters relate to fiscal policy. Constant government spending $G$ is set such that the mean ratio of government spending to annual output is 0.217 , the post-war average. The parameters defining the bounds for debt and the tax levels, $B_{l}, B_{h}, \tau_{l}$ and $\tau_{h}$, are set to satisfy the following four criteria: (i) on average government debt equals 67 percent of GDP, the post-war average for the U.S., (ii) debt may approach zero but never become negative, (iii) debt may approach but never exceed 134 percent of mean annual output, and (iv) the expected durations of high and low tax regimes are the same and thus the unconditional probability of being in either regime is one half. ${ }^{10}$

The only remaining parameter is $\lambda$, which determines the average persistence of tax changes. In the baseline parameterization, this is set so that starting at the initial aggregate state used to plot impulse responses (see table 6 and the discussion in an appendix), expected tax revenue 10 quarters after a tax rise to $\tau_{h}$ or fall to $\tau_{l}$ is equal to initial tax revenue. To get a sense of how sensitive the results are to the persistence of tax changes, I also consider both more and less persistent tax processes in which, starting from the same distribution, tax changes take 16 and 4 quarters to decay. Of course, when changing the persistence of the tax process it is necessary to recompute household decision rules and the equilibrium law of motion for aggregate capital. ${ }^{11}$

\subsection{Variations on the benchmark economy}

Previous quantitative work suggests that weakening inter-generational links in an otherwise Ricardian world does not produce large real effects from temporary

\footnotetext{
${ }^{10}$ A procedure that delivers parameter values with the desired properties is as follows. (i) Set $B_{l}=0$. (ii) Set $B_{h}=2 \times 0.67 \times \mu_{Y}$. (iii) Set $\tau_{h}$ such that 3.1 is an equality. (iv) Set $\tau_{l}$ such that at mean capital and debt $\left(=\left(B_{l}+B_{h}\right) / 2\right),\left.\Delta B\right|_{\tau=\tau_{l}}=-\left.\Delta B\right|_{\tau=\tau_{h}}$. (v) Verify that $\tau_{l}$ does not violate 3.3 .

${ }^{11}$ An alternative metric for the persistence of tax changes is the expected duration of a tax change. The expected durations of a tax increase or decrease in the baseline, high persistence and low persistence paramterizations are $6.8,12.3$, and 3.1 quarters respectively.
} 
tax changes (see the introduction). This leaves capital market imperfections and distortionary taxation as the two primary candidates for generating big deviations from Ricardian equivalence. As a preliminary step towards understanding their relative importance, I compare the benchmark economy described above with an economy in which taxes are proportional to income. In this economy Ricardian equivalence fails both because asset markets are incomplete and because taxes are non-lump-sum. To isolate the distortionary tax effect I also consider a second variation on the benchmark economy in which taxes are proportional but asset markets are complete.

In a final experiment, I examine the extent to which endogenous movements in interest rates are important for my results.

I now describe these variations on the benchmark economy in more detail.

Proportional taxes and incomplete markets

In this economy, I assume that the same marginal tax rate applies to both capital and labor income. Household $i$ 's budget constraint becomes

$$
c_{i t}+a_{i t}=\left[1+\left(1-\tau\left(h^{t}\right)\right) r\left(h^{t-1}\right)\right] a_{i t-1}+\left(1-\tau\left(h^{t}\right)\right) w\left(h^{t-1}\right) e_{i t} \bar{n} .
$$

Government debt now evolves according to

$$
B\left(h^{t}\right)+\tau\left(h^{t}\right)\left[Y\left(h^{t}\right)-\delta K\left(h^{t-1}\right)\right]=\left[1+\left(1-\tau\left(h^{t}\right)\right) r\left(h^{t-1}\right)\right] B\left(h^{t-1}\right)+G .
$$

Most parameters are set to their values in the benchmark (lump-sum tax) economy. The exceptions are the values for the two discount factors, and the two tax rates.

The two values for the discount factor are set so that in a simulation of the economy, the capital to output ratio and the asset holding Gini are the same as in the benchmark economy. I find that satisfying the first criterion requires a higher average discount factor in the proportional tax economy, while satisfying the second requires a smaller difference between the two discount factors (see table 1). Comparing the 'benchmark' and 'prop. tax' columns in table 6, it is clear that the parameterization procedure implies similar asset holding distributions in the lump-sum tax and proportional tax economies.

The two tax rates are set according to a very similar procedure to that described for the lump-sum tax economy, given appropriate adjustments to 3.1 through 3.4. The resulting proportional tax rates are higher than the two values for lump-sum tax revenue relative to steady state output, since only returns to capital net of depreciation are taxed. Because interest earnings on debt are taxed in the proportional tax economy, a smaller gap between $\tau_{l}$ and $\tau_{h}$ is consistent with debt remaining bounded. 
The solution procedure for this economy is very similar to that described for the benchmark economy. Of course, introducing a distortionary tax on asset income means that now it is the after-tax interest rate that appears in the Euler equations describing households' optimal savings decisions. The converged forecasting rule for aggregate capital turns out to be quite similar to that for the economy with lump-sum taxes.

Proportional taxes and complete markets

In this economy agents face no idiosyncratic risk. With this exception, the economy is very similar to the proportional tax economy with incomplete markets described above. In particular, the economy-wide proportional tax rate follows the same stochastic process. The single discount factor is set so that on average the capital output ratio is the same as that in the benchmark economy. Since markets are complete and households are infinitely-lived, any real effects from temporary tax changes in this economy can be attributed to the effect of changes in the extent to which proportional taxation distorts saving decisions.

Exogenous real interest rate and incomplete markets

In this model economy I suppose that the return to saving is fixed exogenously instead of being linked to a production technology. The real interest rate and the real wage are set equal to their average values in a simulation of the benchmark economy. The process for lump-sum taxes and all other parameter values are unchanged relative to the benchmark economy.

\section{Results}

I examine the implications of tax changes in the benchmark model economy in two different ways. First, I describe the economy's behavior over a long simulation during which values for the tax level are drawn according to the specified stochastic process. Second, I plot impulse response functions to one-off tax changes starting from various initial joint distributions over asset holdings and idiosyncratic shocks, and given more and less persistent tax processes.

Having characterized the effects of tax changes in the benchmark economy, I briefly discuss how they differ in the alternative economies described above. 


\subsection{Benchmark economy}

\subsubsection{Simulation}

Consider first the distribution of the consumption response over a simulation 10,000 periods long. ${ }^{12}$ In the two panels on the left-hand side of figure 1 are histograms showing the change in aggregate consumption divided by the change in the aggregate tax level for periods in which taxes went up and periods in which they went down. The overall average response of consumption to tax changes is 14.5 cents per dollar change in tax revenue. This is over twice as large as the response found in models that generate real effects by shortening the households horizon (see the introduction). The consumption response varies dramatically across the simulation, from 3.5 to 24.3 cents per dollar change in tax revenue (see table 2). The consumption response to a tax decrease is typically larger than the response to a tax increase; the average changes in consumption per dollar change in tax revenue are 16 and 13 cents respectively.

To understand why aggregate consumption responds to temporary lump-sum tax changes it is helpful to first look at figure 11 which shows household consumption decision rules across low values for wealth for each possible value for household productivity and the household discount factor. Figure 11 confirms the intuition given in the introduction for why Ricardian equivalence may fail when insurance markets do not exist and households face a no-borrowing constraint. In particular, the optimal consumption choice of low wealth households is lower when taxes are high than when taxes are low, meaning that these households increase consumption following tax cuts and reduce consumption following tax increases. For wealthier households, optimal consumption is much less sensitive to the tax level, implying that richer households respond to tax changes by adjusting their asset holdings rather than their level of consumption.

The consumption of households with both very low wealth and low productivity varies most with the tax level, because these are the households for whom the borrowing constraint binds. Borrowing constrained households are forced to reduce consumption following a tax increase, and see the constraint effectively loosened when taxes are cut. Note, however, that all low wealth households face a positive probability of realizing a sequence of low productivity draws and hitting the constraint in the near future. This probability is decreasing in wealth, and is larger if initial productivity is low. Since households have an incentive to maintain a buffer stock of assets, it is not optimal for any low wealth household

\footnotetext{
${ }^{12}$ An initial joint distribution across individual states was taken from the economy without aggregate uncertainty described in the parameterization section. The full-blown economy was then simulated for 1000 periods before collecting any data.
} 
to completely offset tax changes by adjusting private saving.

The reason for the variation in the aggregate consumption response across a simulation is that the level of government debt and the shape of the joint distribution over asset holdings and income are evolving endogenously through time. The figures in the right hand panels of figure 1 show the distribution of the fraction of households with less than 2 percent of mean assets across dates when the tax level changes. The correlation between the percentage of wealth-poor households and the absolute size of consumption responses is 0.92 , reflecting the sensitivity of low-wealth households' consumption to the tax level.

The consumption response to tax decreases is typically larger than the response to tax increases primarily because there are usually more very poor households in periods in which taxes fall than in periods when they rise: the respective average percentages of the population are 15.5 and 13.6. Forward looking households tend to run down their savings when taxes are high since a high level of public saving reduces the expected future tax burden. An additional explanation has to do with the endogeneity of the real interest rate. Since this is more clearly illuminated with reference to impulse responses, I postpone a discussion to the next section.

Figure 2 describes the variation in several aggregate variables across the simulation. The average values for the ratio of debt to GDP and the net annual real interest rate are 0.67 and 4.5 percent respectively (see the parameterization section). ${ }^{13}$ The histograms in figure 3 show the time series distribution of the average consumption of the asset-poorest quintile, the asset-richest quintile, and the whole population. In each case the mean value for consumption is normalized to one. The distribution for the asset-poorest quintile has high variance and is double-peaked, reflecting the fact that poor households consume less when the tax level is high. There is much less variation in the consumption of rich households, who have sufficient savings to consumption smooth through temporary tax changes. ${ }^{14}$ The average value of the asset holding Gini over the simulation is 0.780 , as in the United States. ${ }^{15}$

\footnotetext{
${ }^{13}$ Large changes in the ratio of government debt to GDP have been observed in the U.S. For example, the ratio of total government debt to GDP rose from 0.47 to 0.87 between 1979 and 1995 (source: Statistical Abstract of the United States).

${ }^{14}$ The low variability of aggregate consumption does not have an economic interpretation, but simply reflects the fact that given a large amount of idiosyncratic uncertainty and a finite population (the sample size here is 4,800 ), the average consumption of the entire population is likely to vary less than that of a given subset.

${ }^{15}$ Weicher $(1997(\mathrm{a}))$ reports that the net worth Gini co-efficient equalled 0.778 in 1983 , that it rose by 0.015 between 1983 and 1989 and that it then fell by 0.006 between 1989 and 1992. The poorest 40 percent of households accounted for 1.6 percent of total asset holdings in 1983, 1.0 percent in 1989 and 1.5 percent in 1992 . Wolff (1994) reports a larger increase in the wealth Gini
} 


\subsubsection{Impulse responses}

The impulse responses in figures 4 through 8 describe in more detail the effects of lump sum tax changes given various initial distributions of wealth and values for outstanding government debt. For each variable considered, the impulse response function shows the immediate response of the variable in the period the tax level changes followed by the expected path of the variable thereafter, conditional on the state of the economy in the impact period. I compute impulse responses starting from different initial asset holding distributions and initial values for outstanding debt. The reason for doing this is that the results of the simulation exercise suggest that the effects of a tax change may be quite sensitive to the aggregate state of the economy. The various starting points and impact effects are described in tables 6 and 7 . Table 8 describes the effect of varying the expected duration of tax changes, holding the initial income and wealth distributions fixed. In an appendix I discuss a few technical issues relating to the mechanics of plotting impulse responses to tax shocks in this model.

\section{Benchmark experiment}

In the benchmark experiment, the initial distribution over wealth and idiosyncratic shocks is very similar to that described in the parameterization section. The wealth Gini is 0.78 and outstanding government debt to output is 67 percent of output.

Figure 4 shows the responses to a tax increase of tax revenue, government debt, aggregate real investment and aggregate real consumption. To better understand the distributional effects of tax changes, I identify the wealth richest and wealth poorest quintiles of the population at the time of the tax change and plot their expected consumption paths in figure 5 .

On impact, aggregate tax revenue rises by 15.2 percent, aggregate consumption falls by 0.9 percent, and investment rises by 3.0 percent. For every extra real dollar of tax revenue the government raises, 15 cents comes from a reduction in consumption while the rest comes from a reduction in household savings. The consumption response of the wealth-poor is much greater than that of aggregate consumption; the poorest 20 percent of the population reduce their consumption by 7 percent on impact (see figure 5). There are no significant short run effects on real output, reflecting the fact that labor supply is fixed.

Figure 6 shows the immediate change in consumption per dollar change in current disposable income (averaging over tax increases and decreases) for each wealth quintile of the population. Poorer households exhibit the largest con-

between 1983 and 1989 of about 0.04 . Thus large changes in the shape of the wealth distribution have been observed within a short period of time (relative to a 2,500 year simulation). 
sumption response to tax changes while wealthier households behave in a more Ricardian way. The fact that the wealthiest households actually increase consumption slightly following a tax increase (and reduce consumption following a tax cut) may be understood as follows. Given constant government spending, a tax increase implies a contemporaneous reduction in the amount of government debt issued and consequently lower future taxes. Understanding this, all households would like to respond to a tax increase by reducing their asset holdings. However, the no-borrowing constraint limits the ability of low-wealth households to dissave. For the market for savings to clear given the new lower supply of debt, either richer households must reduce their asset holdings by more than the increase in the tax level, or else the stock of capital has to rise. In practice both things happen. Capital is crowded in, driving down the real interest rate. This induces rich households to reduce their savings disproportionately and consequently increase their consumption.

The expected paths for consumption and investment inherit the persistence of the expected path for taxes. This means that during a period of high taxes the crowding in process continues, implying a downward sloping path for the expected real interest rate (see figure 5). As the real interest rate falls it becomes increasingly costly to hold precautionary savings. This suggests a further explanation for the finding in the simulation exercise that the fraction of households with very low wealth is increasing prior to tax cuts. It also rationalizes the upward sloping path for the expected asset-holding Gini coefficient.

Low debt experiment

For this experiment I take the starting point of the first example, and then expose the economy to 10 years of the high tax. At the end of this period, outstanding debt has been reduced to 19 percent of output and the wealth Gini is 0.827 . From this point, I shock the economy with a switch to the low tax level, a 26.4 percent cut.

In the period of the tax change, aggregate consumption rises by 3.1 percent while investment falls by 8.1 percent relative to the previous quarter (see table 7 and figure 7). The rise in aggregate consumption now corresponds to 23.9 percent of the rise in taxes. Because the level of debt at the time of the tax cut is low, interest payments on the debt are also low and debt is expected to accumulate only slowly. Given the law of motion for taxes, this means that once taxes are initially cut, they are expected to stay low for a long time. For example, the probability that the tax cut will last at least two quarters is 0.97 compared to 0.87 in the benchmark case.

Why are the real effects of the tax change so much larger than in the benchmark experiment? First, the number of households with zero or very low assets 
is much larger here, magnifying the impact from effectively loosening households' borrowing constraints. Second, recognizing that the tax cut is more persistent in this case, wealth-poor households are less concerned about being thrown back onto their borrowing constraints, and are more willing to increase consumption.

There are two reasons why a large fraction of households are liquidity constrained at the time of the tax cut. The first is that after 10 years of high taxes, enough capital has been crowded in to reduce the interest rate from 4.50 percent to 4.07 percent on an annual basis. This makes it more costly to hold precautionary savings. The second is that lower values of debt imply lower future taxes, further reducing the incentive to accumulate precautionary savings.

\section{High debt experiment}

For this experiment I take the starting point of the benchmark example and then expose the economy to 10 years of low taxes. At the end of this period outstanding debt has risen to 117 percent of output and the wealth Gini is 0.729 . From this point, I shock the economy with a change to the high tax level, a 35.8 percent rise.

The fall in aggregate consumption now corresponds to just 4.3 percent of the rise in taxes. This reflects the fact that all households have accumulated at least some precautionary savings prior to the tax rise. This behavior may be explained by a low cost of saving (prior to the tax increase interest rates rise from 4.50 percent to 4.83 percent) and a high potential benefit given that high debt signals high future taxes.

\section{Varying the persistence of taxes}

Table 8 illustrates the effect of varying the persistence of the tax process. In addition to the baseline parameterization, I compute the response to tax changes which take 4 and 16 quarters to decay (see the parameterization section). To isolate the effect of varying persistence, when computing impulse responses I use the same initial distribution over individual states as for the baseline parameterization.

As one might expect, the more persistent is the process for taxes, the larger are the real effects of a tax change. When the tax change takes 4 years to decay, the response of aggregate consumption is twice as large as when tax revenue is expected to revert to its initial level after only 1 year. Even in the low persistence case, however, the magnitude of the aggregate consumption response remains larger than that attributable to an inter-generational shift of taxes in calibrated life-cycle models (see the introduction), or the response when households are infinitely-lived but taxes are proportional (see the next section). The explanation for why the response remains large is that low-wealth, low-income households are 
always forced to reduce consumption following a tax increase, even if the increase is expected to be very short-lived.

\subsection{Proportional tax economies}

\section{Complete markets}

If asset markets are complete, then under the proportional tax system, a tax increase of 22.8 percent leads to a 0.1 percent increase in aggregate consumption (see table 9). In an economy with infinitely-lived households, complete markets and exogenous labor supply, the only channel through which a change in the income tax rate can have real effects is by changing the effective tax on saving. Thus an increase in the income tax rate temporarily reduces the return to saving, inducing households to substitute away from future consumption and towards current consumption. Note, however, that compared to the incomplete markets economy discussed above, the magnitude of the consumption response is small; the change in aggregate consumption on impact is only 1.3 cents per dollar change in revenue.

\section{Incomplete markets}

If no insurance assets are traded and households are not allowed to borrow, then Ricardian equivalence fails both because asset markets are incomplete and because taxes are distortionary. Given the starting point described in the last column of table 6 , a tax increase leads to a fall in aggregate consumption. The direction of the response is therefore consistent with that found for the benchmark lump-sum tax economy, but the opposite of that for the economy with proportional taxation and complete markets. This finding suggests that for the consumption response to a tax change, the asset market structure is more important than the tax system. ${ }^{16}$

The immediate fall in aggregate consumption is now 8.3 percent of the change in tax revenue. This amounts to 55 percent of the response in the incomplete markets, lump-sum tax economy. One reason for the smaller response has already been discussed: an increase in the tax on capital income provides an incentive for households to increase consumption, partly offsetting the reduction in consumption by liquidity-constrained households. A second reason is that when taxes are proportional, low income, low wealth households face smaller tax bills; in this economy, low income, zero wealth households pay only 59 percent of the average tax burden. This reduces the sensitivity of poor households' consumption to changes in per-capita tax revenue.

\footnotetext{
${ }^{16}$ Of course, this conclusion is subject to the important caveat that labor supply is completely inelastic in these economies.
} 


\subsection{Exogenous real rate economy}

Starting from the benchmark joint distribution over individual states, the average consumption response to a tax change is 47 percent larger in this economy: 22.1 cents per dollar change in revenue versus 15.0 for the economy with an endogenous real interest rate. This difference can be attributed to the fact that in the endogenous real rate economy, tax increases crowd in capital and drive down real interest rates. This in turn increases the incentive for richer households to reduce savings and increase consumption. For the very richest households (who receive a high fraction of their income from savings) this interest rate effect dominates; these households choose to increase consumption in response to a tax increase.

In the economy with a constant real interest rate this interest rate channel does not operate. Recognizing that running down savings increases the probability of being borrowing constrained in the future, all households choose to pay for a positive fraction of a tax increase by reducing current consumption. Of course, the presence of the borrowing constraint still has a larger effect on the consumption behavior of households with lower wealth; the wealth-poorest quintile reduce consumption by 7.3 percent following a tax increase whereas the wealth-richest quintile only reduce consumption by 0.2 percent.

\section{Conclusions}

In a calibrated model economy, borrowing constraints coupled with missing insurance markets are found to imply large short-run real effects from temporary tax changes, even when taxes are lump-sum and households have infinite horizons. Given a wealth distribution and a level of government debt resembling those in the United States, the immediate change in aggregate consumption following a tax change is 15 percent of the change in government revenue.

The consumption of the wealth-poorest households is highly sensitive to changes in the tax level, since the ability of these households to smooth consumption is limited by the presence of the no-borrowing constraint. In contrast, wealthier agents behave in a more Ricardian way, adjusting their savings in response to temporary tax changes. This is not quite the end of the story however. Since tax changes affect aggregate investment, they are associated with movements in the real interest rate which have implications for the consumption / savings behavior of all households. For example, following a tax cut, the real interest rate rises as capital is crowded out. This increases the opportunity cost of current consumption and explains why richer households actually reduce consumption slightly. In an economy with an exogenous real interest rate, the aggregate consumption response to a tax change is found to be 47 percent larger than when the return 
to saving is derived from a production technology.

An important determinant of the size of the aggregate consumption response to a tax change in the model economy is the shape of the asset holding distribution, and in particular the fraction of households with zero or very low wealth. The greater the fraction of wealth-poor households, the larger the effects of tax changes. The typical fraction of households that has very low or zero wealth in a simulation is large (as it is in the United States). This means that averaging across the population, the mean percentage change in household consumption following a tax change is also large. On the other hand, the fact that richer and more Ricardian households account for a disproportionate fraction of total consumption suggests that care should be taken in comparing the findings of empirical work based on micro and macro data.

In a simulation, households move away from the borrowing constraint while taxes are low, both because higher government debt signals higher future taxes, and because rising debt crowds out capital and drives up the real interest rate, reducing the cost of saving. This saving behavior means that the fraction of households with very low wealth tends to be lower at dates when taxes increase than at dates when taxes decrease, and thus explains why tax decreases typically induce larger aggregate consumption responses.

A tentative conclusion to be drawn from the paper is that borrowing constraints appear to be quantitatively more important than distortions arising from the non-lump-sum taxation of capital income. In a complete markets setting, I find that a temporary increase in a proportional income tax induces households to increase consumption, since current consumption is then taxed relatively lightly compared to future consumption. However, with incomplete markets and proportional taxation, the liquidity constraint effect dominates: as in the lump-sum tax economy, consumption responds negatively to tax increases and positively to tax decreases. Extending the model economies of this paper to include labor supply choice would allow for a more complete comparison of the relative importance of distortionary taxes versus borrowing constraints in terms of generating real effects for financing policy. Such an extension would also enable a quantitative assessment of an insurance effect which operates when missing insurance markets mean that distortionary tax changes affect the inter-temporal distribution of idiosyncratic risk. ${ }^{17}$

\footnotetext{
${ }^{17}$ See Barsky, Mankiw and Zeldes (1986), Kimball and Mankiw (1989), Chan (1983), Fremling and Lott (1994), and Croushore (1996).
} 


\section{References}

[1] Aiyagari, S. Rao. 1994. Uninsured idiosyncratic risk and aggregate saving. Quarterly Journal of Economics, 109, 659-684.

[2] Aiyagari, S. Rao and Ellen R. McGrattan. 1998. The optimum quantity of debt. Journal of Monetary Economics, 42, 447-469.

[3] Altig, David and Steve J. Davis. 1989. Government debt, redistributive fiscal policies, and the interaction between borrowing constraints and intergenerational altruism. Journal of Monetary Economics, 24, 3-29.

[4] Auerbach, Alan J. and Laurence J. Kotlikoff. 1987. Dynamic Fiscal Policy, Cambridge University Press.

[5] Barksy, Robert B., N. Gregory Mankiw and Stephen P. Zeldes. 1986. Ricardian consumers with Keynesian propensities. American Economic Review, 76, no. 4, 676-690.

[6] Barro, Robert J. 1974. Are government bonds net wealth? Journal of Political Economy, 82, no. 6, 1095-1117.

[7] Bernheim, B. Douglas. 1987. Ricardian equivalence: An evaluation of theory and evidence. NBER Macroeconomics Annual, 263-304.

[8] Blinder, Alan S. 1981. Temporary income taxes and consumer spending. Journal of Political Economy, 89, no. 1, 26-53.

[9] Braun, Anton. 1994. Tax disturbances and real economic activity in the postwar United States. Journal of Monetary Economics, 33, 247-280.

[10] Cardia, Emanuela. 1997. Replicating Ricardian equivalence tests with simulated series. American Economic Review, 87, no. 1, 65-79.

[11] Castaneda, Ana, Javier Diaz-Gimenez, and Jose-Victor Rios-Rull. 1998. Exploring the income distribution business cycle dynamics. Journal of Monetary Economics, 42, 93-130.

[12] Chan, Louis Kuo Chi. 1983. Uncertainty and the neutrality of government financing policy. Journal of Monetary Economics, 11, 351-372.

[13] Christiano, Lawrence J. and Jonas D. M. Fisher. 1997. Algorithms for solving dynamic models with occasionally binding constraints. Working Paper 97-11. Federal Reserve Bank of Cleveland. 
[14] Cox, Donald and Tullio Jappelli. 1993. The effect of borrowing constraints on consumer liabilities. Journal of Money, Credit and Banking, 25, no. 2, 197-213.

[15] Croushore, Dean. 1996. Ricardian equivalence with wage-rate uncertainty. Journal of Money, Credit and Banking, 28, no. 3, 279-293.

[16] Daniel, Betty C. 1993. Tax timing and liquidity constraints: A heterogeneous-agent model. Journal of Money, Credit and Banking, 25, no. $2,176-196$.

[17] Den Haan, Wouter. 1997. Solving dynamic models with aggregate shocks and heterogeneous agents. Macroeconomic Dynamics, 1, no. 2.

[18] Diaz-Gimenez, Javier, Vincenzo Quadrini, and Jose-Victor Rios-Rull. 1997. Dimensions of inequality: Facts on the U.S. distributions of earnings, income and wealth. Quarterly Review (Spring). Federal Reserve Bank of Minneapolis.

[19] Feldstein, Martin. 1988. The effects of fiscal policies when incomes are uncertain: A contradiction to Ricardian equivalence. American Economic Review, 78 , no. $1,14-23$.

[20] Fremling, Gertrude M. and John R. Lott, Jr. 1994. Do deficits affect the level of insurance? Journal of Money, Credit and Banking, 26, no. 4, 934-940.

[21] Hayashi, Fumio. 1985. The effect of liquidity constraints on consumption: A cross-sectional analysis. Quarterly Journal of Economics, February, 183-206.

[22] Hubbard, Glenn R. and Kenneth L. Judd. 1986. Liquidity constraints, fiscal policy, and consumption. Brookings Papers on Economic Activity, 1, 1-59.

[23] Hubbard, R. Glenn, Jonathan Skinner, and Stephen P. Zeldes. 1995. Precautionary saving and social insurance. Journal of Political Economy, 103, no. 2, 360-399.

[24] Jappelli, Tulio. 1990. Who is credit constrained in the U.S. economy? Quarterly Journal of Economics, February, 219-234.

[25] Kimball, Miles S. and N. Gregory Mankiw. 1989. Precautionary saving and the timing of taxes. Journal of Political Economy, 97, no. 4, 863-879. 
[26] Krusell, Per and Anthony A. Smith Jr. 1997. Income and wealth heterogeneity, portfolio choice, and equilibrium asset returns. Macroeconomic Dynamics; $1(2), 387-422$.

[27] Krusell, Per and Anthony A. Smith Jr. 1998. Income and wealth heterogeneity in the macroeconomy. Journal of Political Economy, 106, no. 5, 867-896.

[28] McGrattan, Ellen. 1994. The macroeconomic effects of distortionary taxation. Journal of Monetary Economics, 33, 573-601.

[29] McGrattan, Ellen. 1997. Applying weighted residual methods to dynamic economic models. Mimeo. Federal Reserve Bank of Minneapolis.

[30] Modigliani, Franco and Charles Steindal. 1977. Is a tax rebate an effective tool for stabilization policy? Brookings Papers on Economics Activity, 1:1977, 175-209.

[31] Poterba, James M. 1988. Are consumers forward looking? Evidence from fiscal experiments. American Economic Review, 78, no. 2, 413-418.

[32] Poterba, James M. and Lawrence H. Summers. 1987. Finite lifetimes and the effects of budget deficits on national saving. Journal of Monetary Economics, 20, 369-391.

[33] Rios-Rull, Jose-Victor. 1997. Computation of equilibria in heterogeneous agent economies. Research Department Staff Report, Federal Reserve Bank of Minneapolis.

[34] Seater, John J. 1993. Ricardian equivalence. Journal of Economic Literature, vol. $31,142-190$.

[35] Shapiro, Matthew D. and Joel Slemrod. 1995. Consumer response to the timing of income: Evidence from a change in tax withholding. American Economic Review, 85, no. 1, 274-283.

[36] Storesletten, Kjetil, Chris Telmer, and Amir Yaron. 1998. Asset pricing with idiosycratic risk and overlapping generations. Mimeo. Institute for International Economic Studies, Stockholm University.

[37] Souleles, Nicholas S. 1997. The response of household consumption to income tax refunds. Mimeo. University of Pennsylvania. 
[38] Tobin, James and Walter Dolde. 1971. Wealth, liquidity and consumption. In Consumer Spending and Monetary Policy, Federal Reserve Bank of Boston, 99-146.

[39] Trostel, Philip A. 1993. The nonequivalence between deficits and distortionary taxation. Journal of Monetary Economics 31, 207-227.

[40] Wilcox, David W. 1989. Social security benefits, consumption expenditure, and the life cycle hypothesis. Journal of Political Economy, 97, no. 2, 288304.

[41] Weicher, John. 1997(a). The distribution of wealth, 1983-1992: Secular growth, cyclical stability. Federal Reserve Bank of St. Louis Review, 79(1), $3-23$.

[42] Weicher, John. 1997(b). The rich and the poor: Demographics of the U.S. wealth distribution. Federal Reserve Bank of St. Louis Review, 79(4), 25-37.

[43] Wolff, Edward N. 1994. Trends in household wealth in the United States, 1962-83 and 1983-89. Review of Income and Wealth, 143-174.

[44] Woodford, Michael. 1990. Public debt as private liquidity. American Economic Review, 80, no. 2, 382-388.

[45] Zeldes, Stephen P. 1989. Consumption and liquidity constraints: An empirical investigation. Journal of Political Economy, 97, no. 2, 305-346.

\section{Appendices}

\subsection{Definition of equilibrium (with lump-sum taxation)}

Household $i$ solves

$$
\max _{\left\{a_{i t}\right\}} E_{0} \sum_{t=0}^{\infty} u\left(c_{i t}\right) \theta_{i t}
$$

subject to $\forall t$ and $\forall h^{t} \in H^{t}$

$$
\begin{gathered}
c_{i t}+a_{i t}=\left(1+r\left(h^{t-1}\right)\right) a_{i t-1}+w\left(h^{t-1}\right) e_{i t} \bar{n}-\tau\left(h^{t}\right), \\
c_{i t} \geq 0, \quad a_{i t} \in \mathcal{A},
\end{gathered}
$$

taking as given sequences $\left\{r\left(h^{t}\right)\right\},\left\{w\left(h^{t}\right)\right\}$ and $\left\{\tau\left(h^{t}\right)\right\}$, the initial individual state $s_{i 0}$, the Markov processes $\pi_{e}$ and $\pi_{\beta}$, and unconditional probabilities over histories, $\left\{\rho\left(h^{t}\right)\right\}$. 
Let $a^{\prime}\left(s ; h^{t}\right)$ denote the optimal value for savings at date $t$ given individual state $s$ and history $h^{t}$. The decision rule $a^{\prime}\left(\cdot ; h^{t}\right)$ together with the processes for $e$ and $\beta$ define a Markov process for the individual state vector $s$ with date and state varying transitions. Let $T\left(s, U ; h^{t}\right)$ be the value of a transition function corresponding to the probability that an agent in individual state $s$ at $h^{t}$ will have an individual state that lies in the set $U$ in $t+1$.

An equilibrium is a collection of stochastic processes for measures $\left\{\psi_{t}\left(\cdot ; h^{t-1}\right)\right\}$, prices $\left\{r\left(h^{t}\right)\right\}$ and $\left\{w\left(h^{t}\right)\right\}$, aggregate capital, debt and asset holdings $\left\{K\left(h^{t}\right)\right\}$, $\left\{B\left(h^{t}\right)\right\}$ and $\left\{A\left(h^{t}\right)\right\}$, taxes $\left\{\tau\left(h^{t}\right)\right\}$, decision rules $\left\{a^{\prime}\left(\cdot ; h^{t}\right)\right\}$ and transition functions for individual states $\left\{T\left(\cdot, \cdot ; h^{t}\right)\right\}$ such that $\forall t$ and $\forall h^{t} \in H^{t}$ :

- 1. $a^{\prime}\left(\cdot ; h^{t}\right)$ solves the household's problem above given the stochastic processes for productivity and patience and $\left\{r\left(h^{t}\right)\right\},\left\{w\left(h^{t}\right)\right\}$, and $\left\{\tau\left(h^{t}\right)\right\}$.

- 2. $T\left(\cdot, \cdot ; h^{t}\right)$ is consistent with $a^{\prime}\left(\cdot ; h^{t}\right)$ and the given Markov processes for productivity and patience in that for all $s \in \mathcal{S}$ and for all $U \in \mathcal{S}$,

$$
T\left(s, U ; h^{t}\right)=\sum_{e \in E} \sum_{\beta \in \beta} I\left\{\left(e, \beta, a^{\prime}\left(s ; h^{t}\right)\right) \in U\right\} \times \pi_{e}(e \mid s) \pi_{\beta}(\beta \mid s)
$$

where $I$ is an indicator function.

- 3. $\psi_{t+1}\left(\cdot ; h^{t}\right)$ is consistent with $T\left(\cdot, \cdot ; h^{t}\right)$ and $\psi_{t}\left(\cdot ; h^{t-1}\right)$ in that for all $U \in \mathcal{S}$ and for all $h^{t}$ compatible with $h^{t-1}$,

$$
\psi_{t+1}\left(U ; h^{t}\right)=\int_{S} T\left(\cdot, U ; h^{t}\right) d \psi_{t}\left(\cdot ; h^{t-1}\right) .
$$

- 4. The market for savings clears.

$$
K\left(h^{t}\right)+B\left(h^{t}\right)=\int_{S} a^{\prime}\left(\cdot ; h^{t}\right) d \psi_{t}\left(\cdot ; h^{t-1}\right)=A\left(h^{t}\right) .
$$

- 5. Factor markets clear.

$$
\begin{gathered}
r\left(h^{t-1}\right)=\alpha K\left(h^{t-1}\right)^{\alpha-1} \bar{n}^{1-\alpha}-\delta . \\
w\left(h^{t-1}\right)=(1-\alpha) K\left(h^{t-1}\right)^{\alpha} \bar{n}^{-\alpha} .
\end{gathered}
$$

- 6. The unconditional probabilities over histories are consistent with the law of motion for taxes in that for all $j \in \tau$

$$
\rho\left(h_{j}^{t+1}\right)=\pi_{\tau}\left(j \mid \tau\left(h^{t}\right), B\left(h^{t}\right)\right) \rho\left(h^{t}\right),
$$

where $h_{j}^{t+1}$ denotes the history consisting of $h^{t}$ followed by $\tau_{t+1}=j$. 
- 7. The government budget constraint is satisfied and debt remains bounded.

$$
\begin{gathered}
B\left(h^{t}\right)+\tau\left(h^{t}\right)=\left(1+r\left(h^{t-1}\right)\right) B\left(h^{t-1}\right)+G \quad \forall h^{t} \text { compatible with } h^{t-1} . \\
B\left(h^{t}\right) \in \mathcal{D} .
\end{gathered}
$$

- 8. The goods market clears.

$$
C\left(h^{t}\right)+G+K\left(h^{t}\right)=Y\left(h^{t}\right)+(1-\delta) K\left(h^{t-1}\right) \quad \forall h^{t} \text { compatible with } h^{t-1} .
$$

\subsection{The revised household problem}

Recall that in the revised household problem, the aggregate state of the economy is summarized by the vector $Z=\left(K_{-1}, B_{-1}, \tau\right)$. A household's individual state is given by $s=\left(e, \beta, a_{-1}\right)$.

With the problem described recursively, households solve

$$
V(s, Z)=\max _{a}\left\{u(c)+\beta E\left[V\left(s^{\prime}, Z^{\prime}\right) \mid s, Z\right]\right\}
$$

subject to

$$
\begin{gathered}
c+a=(1+r(Z)) a_{-1}+w(Z) e \bar{n}-\tau \\
c \geq 0, a \in \mathcal{A}
\end{gathered}
$$

taking as given the Markov processes $\pi_{e}, \pi_{\beta}$ and $\pi_{\tau}$, functions for factor prices,

$$
\begin{aligned}
& r(Z)=\alpha K_{-1}^{\alpha-1} \bar{n}^{1-\alpha}-\delta \\
& w(Z)=(1-\alpha) K_{-1}^{\alpha} \bar{n}^{-\alpha}
\end{aligned}
$$

the law of motion for debt,

$$
B+\tau=(1+r(Z)) B_{-1}+G
$$

and a law of motion for aggregate capital of the form

$$
\ln K=\alpha_{0}+\alpha_{1} \ln K_{-1}+\alpha_{2} B_{-1}+\alpha_{3} \ln \tau .
$$

In this law of motion or forecasting rule the $\alpha$ 's are initially arbitrary constants. 


\subsection{Solving the household's problem}

The state space for this problem is large. There are three continuous states, $a, K_{-1}$, and $B_{-1}$, and three discrete states, $e, \beta$ and $\tau$. Moreover, given that markets are incomplete and agents face a borrowing constraint that may or may not be binding, it is clear that a global solution method is appropriate. I solve the consumer's problem using the finite element method as outlined by McGrattan (1997). The method involves searching for piecewise linear decision rules that imply small Euler equation residuals across the state space. The grid I use has 30 points in the individual assets dimension, and 3 points in both the aggregate capital and aggregate debt dimensions. Given two values for each of the discrete states, the total number of grid points is 2160 .

The Euler equation for the household's problem is

$$
-u^{\prime}(c)+\beta E\left[\left(1+r\left(Z^{\prime}\right)\right) u^{\prime}\left(c^{\prime}\right)\right]+\mu=0
$$

where $\mu \geq 0$ and $\mu a^{\prime}=0$. Here $\mu$ is a multiplier associated with the nonnegativity constraint on asset holdings. To evaluate the Euler equation residual across the state space we require functions $c(s, Z)$ (or alternatively $a^{\prime}(s, Z)$ ) and $\mu(s, Z)$.

McGrattan avoids having to solve for a function $\mu(s, Z)$ by introducing a penalty function on negative asset holdings and getting rid of the explicit noborrowing constraint. This method is time consuming since the problem has to be repeatedly resolved with increasing values for the penalty.

The approach taken here is more reminiscent of the parameterized expectations algorithm advocated by Christiano and Fischer (1997). This method involves solving for a single unknown function $Q(s, Z)$ corresponding to a transformation of the conditional expectation in the original Euler equation. Given this function it is straightforward to compute $c$ and $\mu$ for any values of $s$ and $Z$ as follows.

Step 1: Let $Q=\left(\beta E\left[(1+r(K)) c^{\prime-\gamma}\right]\right)^{\frac{-1}{\gamma}}$. The Euler equation may now be written as

$$
-u^{\prime}(c)+Q^{-\gamma}+\mu=0
$$

Step 2: Consider the mutually exclusive possibilities for the $(\mu, a)$ pair that satisfy complementary slackness.

Possibility $1 \mu \geq 0, \quad a=0$

$$
a=0 \Rightarrow c=(1+r) a_{-1}+w e \bar{n}-\tau
$$




$$
\mu=c^{-\gamma}-Q^{-\gamma} \geq 0 \Leftrightarrow c \leq Q
$$

Possibility $2 \mu=0, \quad a>0$

$$
\begin{gathered}
\mu=0 \Rightarrow c^{-\gamma}-Q^{-\gamma}=0 \Leftrightarrow c=Q \\
a=(1+r) a_{-1}+w e \bar{n}-\tau-c
\end{gathered}
$$

Step 3: Given $Q$, check whether $(1+r) a_{-1}+w e \bar{n}-\tau \leq Q$. If it is then possibility 1 applies and $a=0$. If it is not then possibility 2 applies and $c=Q$.

Step 4: Given $Q$ and $c$ or $a$ it is straightforward to recover all other variables using the household budget constraint and 6.1.

\subsection{The Krusell and Smith method}

Given a method for computing $a^{\prime}(s, Z)$ the Krusell and Smith approach for deriving a forecasting rule for aggregate capital is as follows.

First, specify an initial vector of $\alpha$ parameters, an initial measure across individual states $\psi_{0}$ (with a large but finite number of agents), an initial tax level $\tau_{0}$, and an initial value for outstanding government debt, $B_{-1}$. Compute aggregate capital, $K_{-1}$, by subtracting aggregate debt from aggregate asset holdings.

Now given $\psi_{0}$ and $\alpha$, compute decision rules across the state space and use these decision rules to construct $T$. Compute $\psi_{1}$ by applying $T$ across $\psi_{0}$.

Use $\psi_{1}$, the government budget constraint, and the transition function for taxes to compute $Z_{1}=\left(K_{0}, B_{0}, \tau_{1}\right)$ given $Z_{0}$.

Repeat this procedure for a large number of periods to generate time series for $Z$. Use this time series to update the guesses for the parameter values in the forecasting rule for aggregate capital by running a regression.

Repeat the entire process of solving the households' problems, simulating the economy and updating parameter values until the forecasting rule for aggregate capital converges. At the converged $\alpha$ vector the forecasting rule households use when solving their problems is such that their behavior generates a law of motion for capital for which the best linear predictor is the same forecasting rule.

For the parameterization described in the paper, the converged value for $\alpha_{1}$ is close to but less than 1 . The converged value for $\alpha_{2}$ is negative, indicating that ceteris paribus more debt implies less investment and consequently a smaller next period capital stock. The converged value for $\alpha_{3}$ is positive, indicating that investment tends to be higher when the tax level is high. 


\subsection{Computing impulse responses}

There are two slightly troublesome issues to be dealt with before graphing impulse responses to tax shocks. The first concerns how to plot the expected path of variables given that the tax level is a discrete state assuming only two values. The second concerns the choices of appropriate initial values for aggregate capital and debt, and the initial joint distribution over asset holdings and idiosycratic shocks.

The expected path of a variable from the date at which taxes change, $x$, to some future date, $x+n$, is computed as follows. Given that there are two possible tax levels at each date, the number of possible paths for taxes over this horizon is $2^{n}$. For each possible path for taxes, the model implies a unique equilibrium sequence for each aggregate variable, which can be computed given household decision rules. The expected path for a variable is just a weighted sum of these paths, where the weights are given by the probabilities at date $x$ that the corresponding tax sequence will transpire. Note that these probabilities are endogenous, since the transition function for the tax level takes aggregate government debt as one of its arguments, and the level of government debt is endogenous.

The issue of choosing a starting point for plotting impulse responses arises because the simulation results indicate that the effects of tax changes are quite sensitive to the shape of the asset holding distribution and to the quantity of aggregate government debt, both of which change as the economy is hit by aggregate tax shocks. To examine what might be considered a typical tax change, I would like to plot impulse responses starting from an aggregate state characterized by average values for capital, governmnent debt, tax revenue and wealth concentration. To construct a wealth distribution with these features I use a variant of the model economy which does not have risk at the aggregate level, and which therefore implies a stationary equilibrium asset holding distribution. To ensure that in the economy without aggregate risk agents face a similar overall amount of risk as agents in the economy with aggregate tax shocks, I compute the steady state allocations for an economy in which households face no aggregate tax shocks, but where they do face additional idiosyncratic income shocks with the same magnitude and persistence as the tax shocks in the benchmark economy. Thus in the steady state of the economy without aggregate risk, half of households pay taxes at the low level, while the remainder are taxed at the high level. I define a tax increase from this point to be a move to a situation in which all households pay the high lump sum tax. To compute the expected paths for variables following a tax increase, I use the decision rules for the full-blown economy with aggregate uncertainty and suppose that from the date of the initial 
increase on, the lump-sum tax level is an aggregate rather than an idiosyncratic state. Instead of reporting the results for tax increases and decreases seperately, in figures 4 and 5 I plot the average of the expected path following a tax increase and the negative of the expected path following a tax decrease.

\subsection{Tables}

Table 1: Parameter values (quarterly basis)

\begin{tabular}{|c|c|c|c|c|}
\hline & 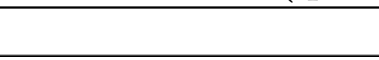 & Asse & markets and & ses \\
\hline & & Incomplete & Incomplete & Complete \\
\hline & & Lump-sum & Proportional & Proportional \\
\hline Aggregate & $\alpha$ & 0.3 & & \\
\hline Production & $\delta$ & 0.018935 & & \\
\hline Individual & $e_{h}$ & 1.291 & & 1.0 \\
\hline productivity & $e_{l}$ & 0.709 & & 1.0 \\
\hline & $\pi_{e}\left(e_{h} \mid e_{l}\right)$ & 0.06 & & \\
\hline & $\pi_{e}\left(e_{l} \mid e_{h}\right)$ & 0.06 & & \\
\hline Preferences & $\gamma$ & 1.0 & & \\
\hline & & 0.99031 & 0.99325 & 0.99224 \\
\hline & $\beta_{l}$ & 0.98101 & 0.98872 & 0.99224 \\
\hline & $\pi_{\beta}\left(\beta_{h} \mid \beta_{l}\right)$ & 0.00056 & & \\
\hline & $\pi_{\beta}\left(\beta_{l} \mid \beta_{h}\right)$ & 0.00167 & & \\
\hline Government & $G / \bar{Y}$ & 0.217 & & \\
\hline & $\tau_{h}$ & $\tau_{h} / \bar{Y}=0.284$ & $\tau_{h}=0.327$ & $\tau_{h}=0.327$ \\
\hline & $\tau_{l}$ & $\tau_{l} / \bar{Y}=0.209$ & $\tau_{l}=0.261$ & $\tau_{l}=0.261$ \\
\hline & $B_{l} / \bar{Y}$ & 0 & & \\
\hline & $B_{h} / \bar{Y}$ & 1.34 & & \\
\hline & & $0.2(0.870)$ & & \\
\hline & $\lambda\left(\right.$ and $\left.\pi_{\tau}\left(\tau_{i} \mid \tau_{i}, \mu_{B}\right)\right)$ & $0.095(0.936)$ & $0.2(0.870)$ & $0.2(0.870)$ \\
\hline & & $0.525(0.694)$ & & \\
\hline
\end{tabular}


Table 2: Values across a 10,000 period simulation

\begin{tabular}{l|ccc}
\hline & Average & Minimim & Maximum \\
\hline Debt to GDP & 0.671 & 0.179 & 1.172 \\
Capital to GDP & 2.501 & 2.434 & 2.583 \\
Consumption to GDP & 0.594 & 0.575 & 0.608 \\
Investment to GDP & 0.189 & 0.173 & 0.210 \\
Gov. cons. to GDP & 0.217 & 0.214 & 0.219 \\
Real interest rate (net p.a.) & 4.50 & 4.10 & 4.84 \\
Wealth Gini & 0.781 & 0.732 & 0.825 \\
$\mathrm{C}_{r} / \mathrm{C}_{p}{ }^{18}$ & 3.46 & 2.85 & 4.47 \\
$\% \leq 0^{19}$ & 6.6 & 0.0 & 17.5 \\
$\% \leq 0.02 \mu_{a}{ }^{20}$ & 14.6 & 5.3 & 24.4 \\
$\% \leq 0.02 \mu_{a}$ t.i. $^{21}$ & 13.6 & 5.7 & 21.4 \\
$\% \leq 0.02 \mu_{a}$ t.d. $^{22}$ & 15.5 & 6.6 & 24.2 \\
$100 \times \Delta \mathrm{C} / \Delta \tau$ t.i. $^{23}$ & 13.0 & 4.0 & 22.1 \\
$100 \times \Delta \mathrm{C} / \Delta \tau$ t.d. $^{24}$ & 16.0 & 3.5 & 24.3
\end{tabular}

Table 3: Correlations across a 10,000 period simulation

\begin{tabular}{l|cccccccc}
\hline & $B$ & $K$ & $\%$ & $C$ & $C_{r}$ & $C_{p}$ & $X$ & $\tau$ \\
\hline Debt, $B$ & 1.00 & -0.79 & -0.72 & -0.23 & 0.54 & -0.09 & -0.20 & 0.27 \\
Capital, $K$ & & 1.00 & 0.87 & 0.23 & 0.05 & -0.09 & 0.31 & -0.17 \\
$\% \leq 0.02 \mu_{a}, \%$ & & & 1.00 & -0.12 & 0.09 & -0.36 & 0.58 & 0.04 \\
Cons., $C$ & & & & 1.00 & -0.20 & 0.91 & -0.85 & -0.91 \\
Cons. rich, $C_{r}$ & & & & & 1.00 & -0.42 & 0.22 & 0.31 \\
Cons. poor, $C_{p}$ & & & & & & 1.00 & -0.94 & -0.91 \\
Investment, $X$ & & & & & & & 1.00 & 0.80 \\
Tax revenue, $\tau$ & & & & & & & & 1.00
\end{tabular}

\footnotetext{
${ }^{18}$ Ratio of the average consumptions of the wealth richest and wealth poorest quintiles.

${ }^{19}$ Percentage of households with zero asset holdings.

${ }^{20}$ Percentage of households with less than 2 percent of mean asset holdings.

${ }^{21}$ Percentage of households with less than 2 percent of mean asset holdings in periods when the tax level rises.

${ }^{22}$ Percentage of households with less than 2 percent of mean asset holdings in periods when the tax level falls.

${ }^{23}$ Change in aggregate consumption per dollar change in tax revenue in periods when the tax level rises.

${ }^{24}$ Change in aggregate consumption per dollar change in tax revenue in periods when the tax level falls.
} 
Table 4: Mobility in the U.S. ${ }^{25}$

\begin{tabular}{|c|c|c|c|c|c|c|}
\hline \multicolumn{7}{|c|}{$\begin{array}{l}\text { \% of households in each quintile in } 1984 \\
\text { in each quintile in } 1989\end{array}$} \\
\hline Measure & 1984 Quintile & \multicolumn{5}{|c|}{1989 Quintile } \\
\hline & & 1 & 2 & 3 & 4 & 5 \\
\hline \multirow[t]{5}{*}{ Wealth $^{26}$} & 1 & 66.7 & 23.4 & 6.6 & 2.9 & 0.4 \\
\hline & 2 & 25.4 & 46.6 & 20.4 & 5.4 & 2.3 \\
\hline & 3 & 5.8 & 24.4 & 44.9 & 20.5 & 4.6 \\
\hline & 4 & 1.8 & 4.6 & 22.4 & 49.6 & 21.6 \\
\hline & 5 & 0.7 & 0.8 & 5.7 & 21.6 & 71.2 \\
\hline \multirow[t]{5}{*}{ Income $^{27}$} & 1 & 71.0 & 17.9 & 7.0 & 2.9 & 1.3 \\
\hline & 2 & 19.5 & 43.8 & 22.9 & 10.1 & 3.7 \\
\hline & 3 & 5.1 & 25.5 & 37.2 & 24.9 & 7.3 \\
\hline & 4 & 2.5 & 10.7 & 23.4 & 42.5 & 20.8 \\
\hline & 5 & 1.9 & 2.1 & 9.5 & 20.3 & 66.3 \\
\hline
\end{tabular}

Table 5: Mobility in the model

\begin{tabular}{|c|c|c|c|c|c|c|}
\hline \multicolumn{7}{|c|}{$\begin{array}{l}\% \text { of households in each quintile } \\
\text { in each quintile } 20 \text { quarters later }\end{array}$} \\
\hline \multirow[t]{2}{*}{ Measure } & \multirow[t]{2}{*}{ Quintile at $t$} & \multicolumn{5}{|c|}{ Quintile at $t+20$} \\
\hline & & 1 & 2 & 3 & 4 & 5 \\
\hline \multirow[t]{5}{*}{ Wealth } & 1 & 47.8 & 32.4 & 19.1 & 0.7 & 0.0 \\
\hline & 2 & 33.0 & 28.2 & 32.3 & 6.5 & 0.0 \\
\hline & 3 & 17.3 & 25.0 & 26.0 & 31.7 & 0.0 \\
\hline & 4 & 1.9 & 14.5 & 22.4 & 57.0 & 4.2 \\
\hline & 5 & 0.0 & 0.0 & 0.0 & 4.2 & 95.8 \\
\hline \multirow[t]{5}{*}{ Income } & 1 & 45.1 & 7.8 & 35.1 & 12.0 & 0.1 \\
\hline & 2 & 34.0 & 19.2 & 21.7 & 19.7 & 5.4 \\
\hline & 3 & 14.6 & 20.5 & 23.0 & 27.8 & 14.2 \\
\hline & 4 & 6.4 & 39.8 & 5.3 & 37.1 & 11.4 \\
\hline & 5 & 0.0 & 12.8 & 14.9 & 3.4 & 69.0 \\
\hline
\end{tabular}

\footnotetext{
${ }^{25}$ This table is taken from Diaz-Gimenez, Quadrini and Rios-Rull (1997) and is based on data from the Panel Study of Income Dynamics.

${ }^{26}$ Diaz-Gimenez et. al. define wealth as the net value of all kinds of real and financial assets. The corresponding object for household $i$ in the model is $a_{i}$.

${ }^{27}$ Diaz-Gimenez et. al. define income as all kinds of revenue before taxes. The corresponding object for household $i$ in the model is $r a_{i}+w e_{i} \bar{n}$.
} 
Table 6: Starting points for impulse responses

\begin{tabular}{c|ccccc}
\hline & U.S. & Benchmark & Low Debt & High Debt & Prop. Tax \\
\hline 100×Debt/GDP & 67 & 67 & 19 & 117 & 67 \\
Annual $r$ & & 4.50 & 4.07 & 4.83 & 4.50 \\
& & & & & \\
Wealth Gini & 0.78 & 0.780 & 0.827 & 0.729 & 0.780 \\
$99-100 \%$ & 29.6 & 18.4 & 20.5 & 16.9 & 18.5 \\
$90-100 \%$ & 66.1 & 66.3 & 71.6 & 61.6 & 65.7 \\
$80-100 \%$ & 79.5 & 84.2 & 89.3 & 79.3 & 84.0 \\
$10-40 \%$ & 1.9 & 2.2 & 0.9 & 4.0 & 2.1 \\
$0-40 \%$ & 1.4 & 2.2 & 0.9 & 4.3 & 2.1 \\
$\%$ with $\leq 0$ assets & 6.9 & 5.1 & 18.2 & 0.0 & 7.6
\end{tabular}

Table 7: Initial effects of tax changes

Benchmark economy, alternative starting points

\begin{tabular}{l|ccc}
\hline Starting point & \multicolumn{3}{|c}{ \%enchmark } \\
& $\begin{array}{c}\text { Low Debt } \\
\text { chan impact }\end{array}$ & High Debt \\
\hline Tax revenue & 15.19 & -26.37 & 35.82 \\
Aggregate consumption & -0.94 & 3.07 & -0.53 \\
Aggregate investment & 2.97 & -8.12 & 1.68 \\
Consumption of richest quintile & 0.14 & -0.11 & 0.24 \\
Consumption of poorest quintile & -6.97 & 7.45 & -0.92 \\
$100 \times|\Delta C / \Delta \tau|$ & 15.0 & 23.9 & 4.3
\end{tabular}

Table 8: Initial effects of tax changes

Benchmark starting point, varying persistence

\begin{tabular}{l|ccc}
\hline $\begin{array}{l}\text { Expected time to decay } \\
\text { of tax change (quarters) }\end{array}$ & 10 & 4 & 16 \\
& \% change on & impact \\
\hline Tax revenue & 15.19 & 15.19 & 15.19 \\
Aggregate consumption & -0.94 & -0.63 & -1.28 \\
Aggregate investment & 2.97 & 1.97 & 4.00 \\
Consumption of richest quintile & 0.14 & 0.04 & 0.30 \\
Consumption of poorest quintile & -6.97 & -4.96 & -8.38 \\
$100 \times|\Delta C / \Delta \tau|$ & 15.0 & 9.9 & 20.2
\end{tabular}


Table 9: Initial effects of tax changes Alternative economies

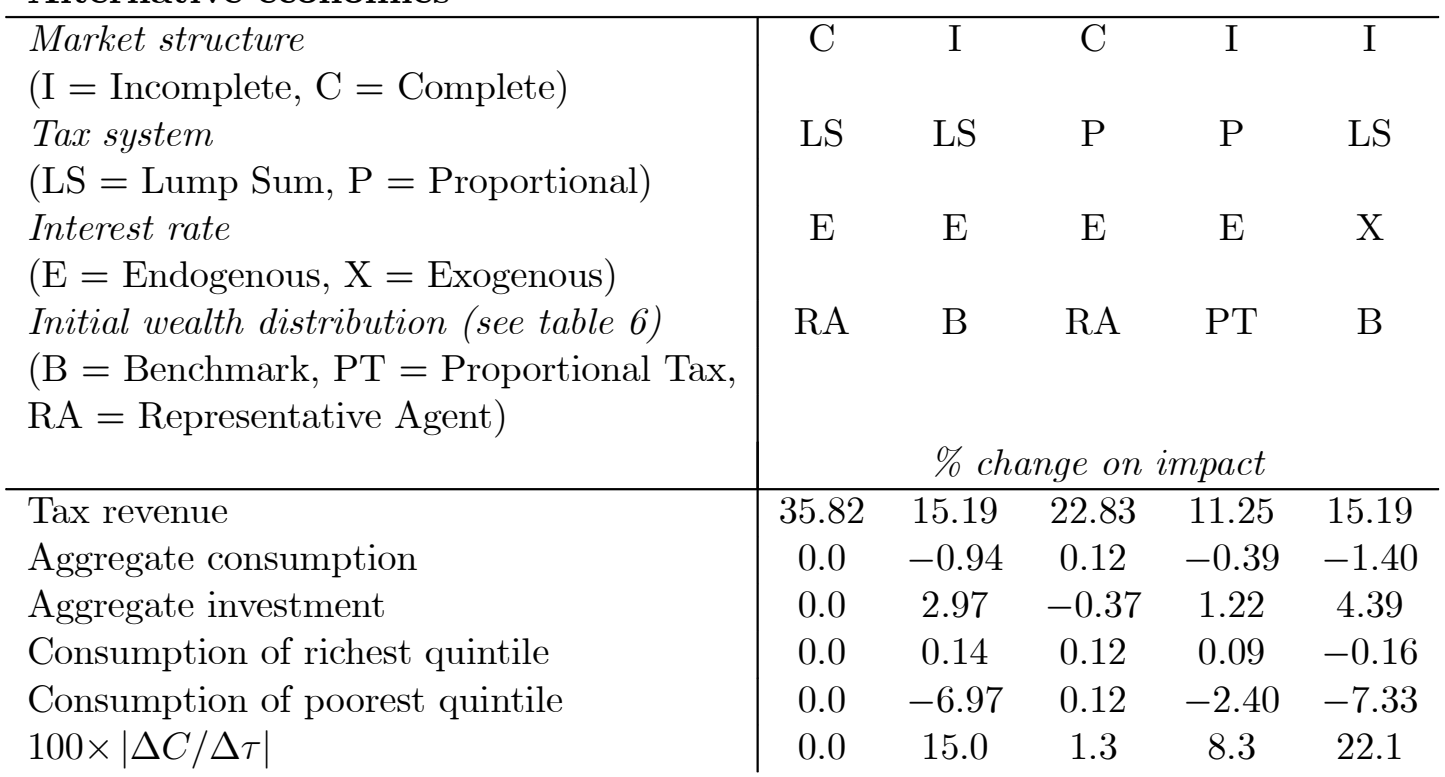


Figure 1: Tax Increases vs Tax Decreases

Consumption Responses to Increases

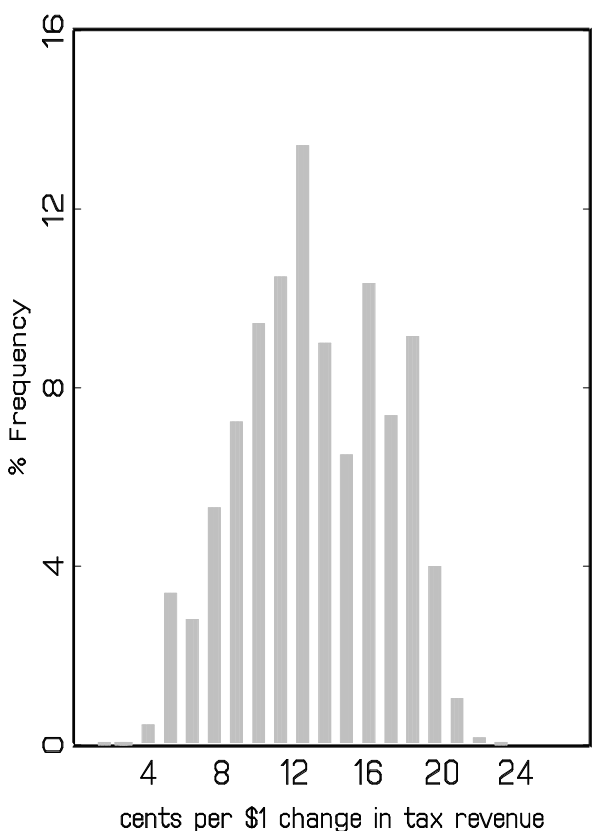

Consumption Responses to Cuts

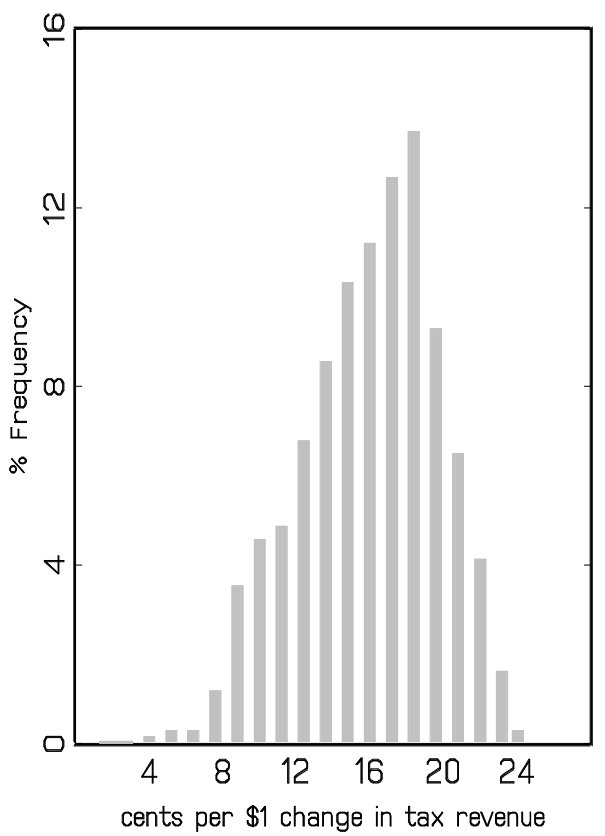

No. of Poor when Taxes Rise

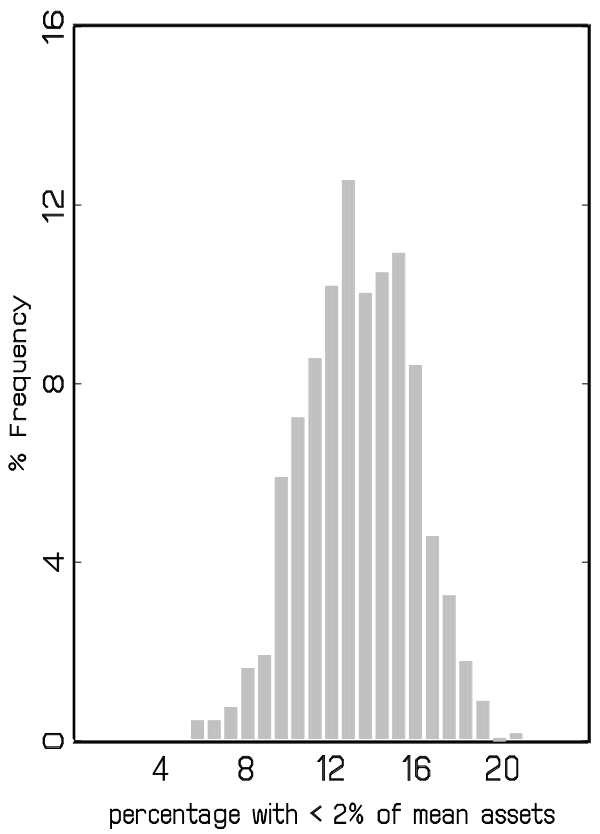

No. of Poor when Taxes Fall

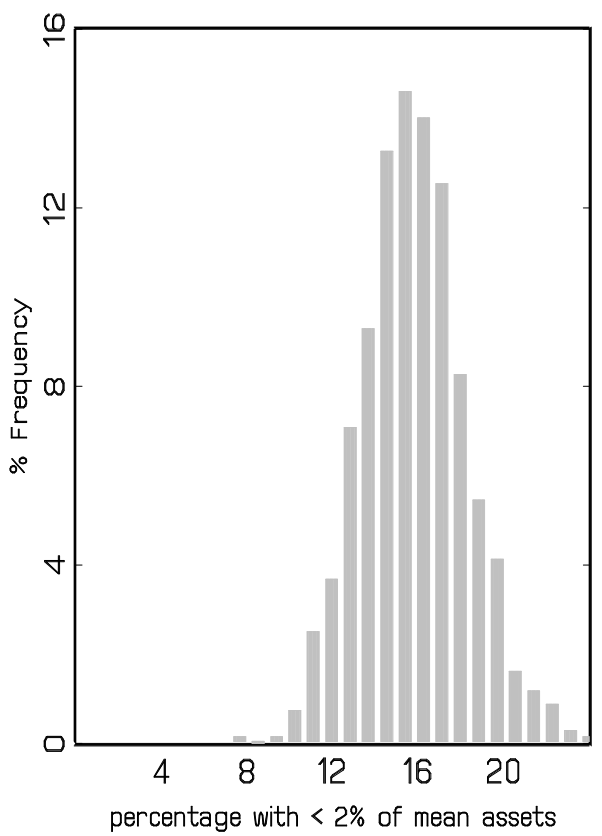


Figure 2: Variation in Debt, Capital,

Real Interest Rate and Investment

Distribution of Debt

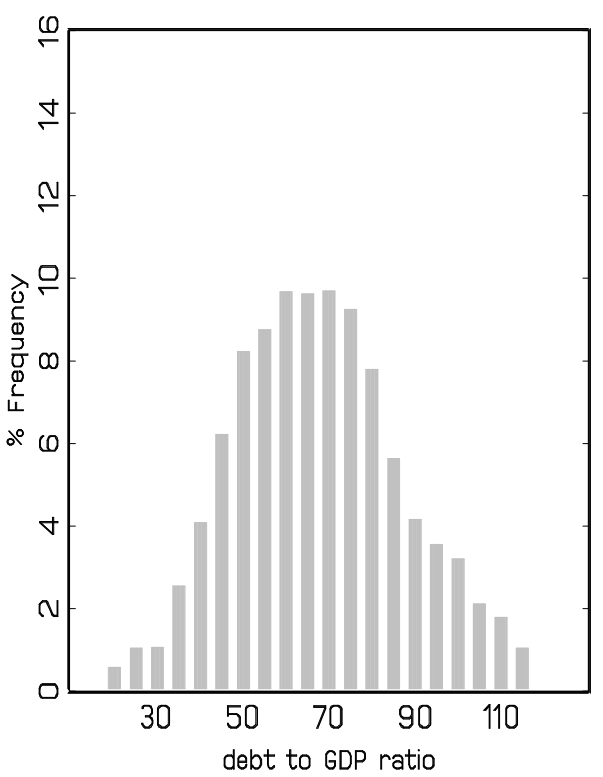

Annualized Real Interest Rate

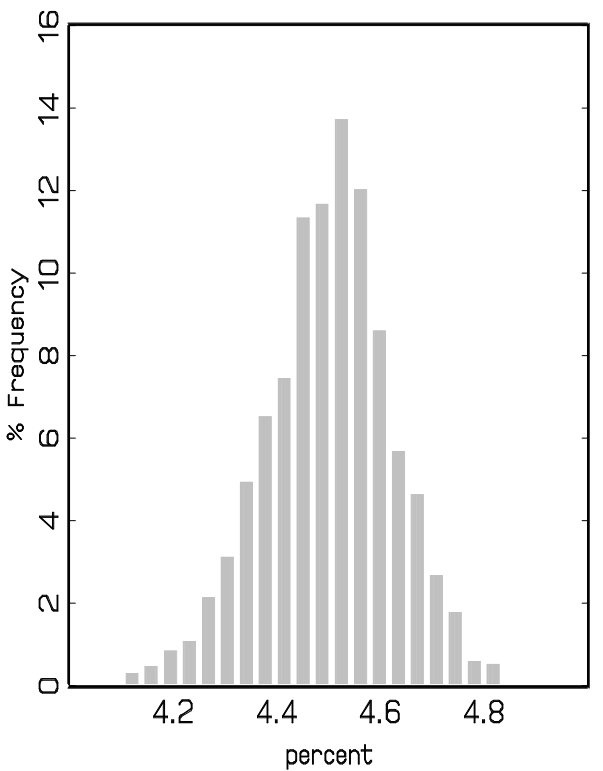

Distribution of Capital Stock

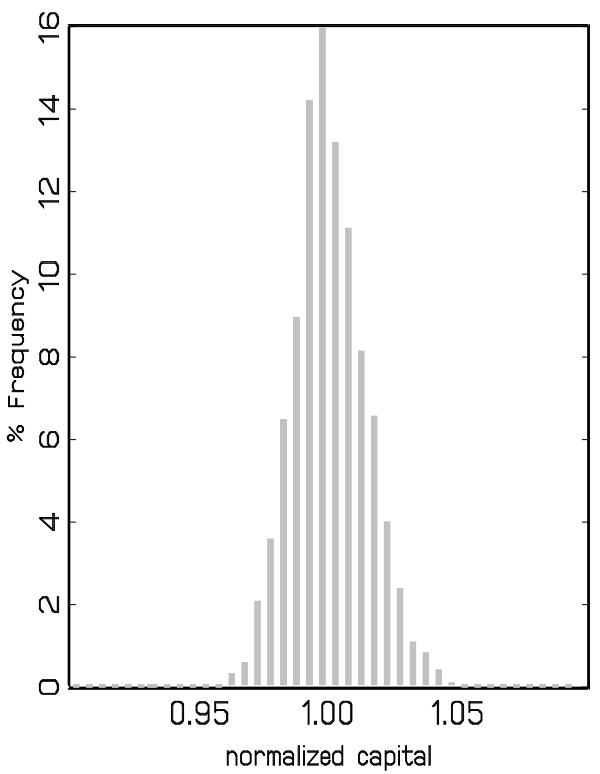

Distribution of Agg Investment

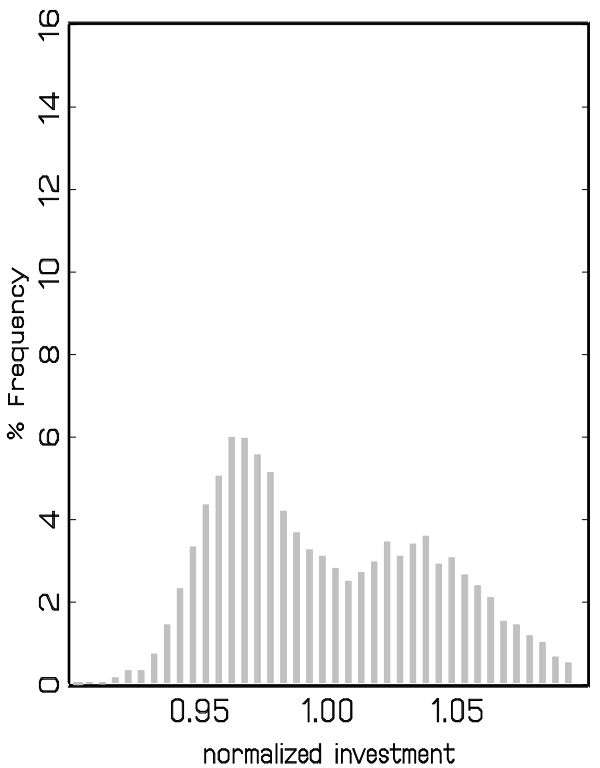


Figure 3: Variation in Consumption and Gini
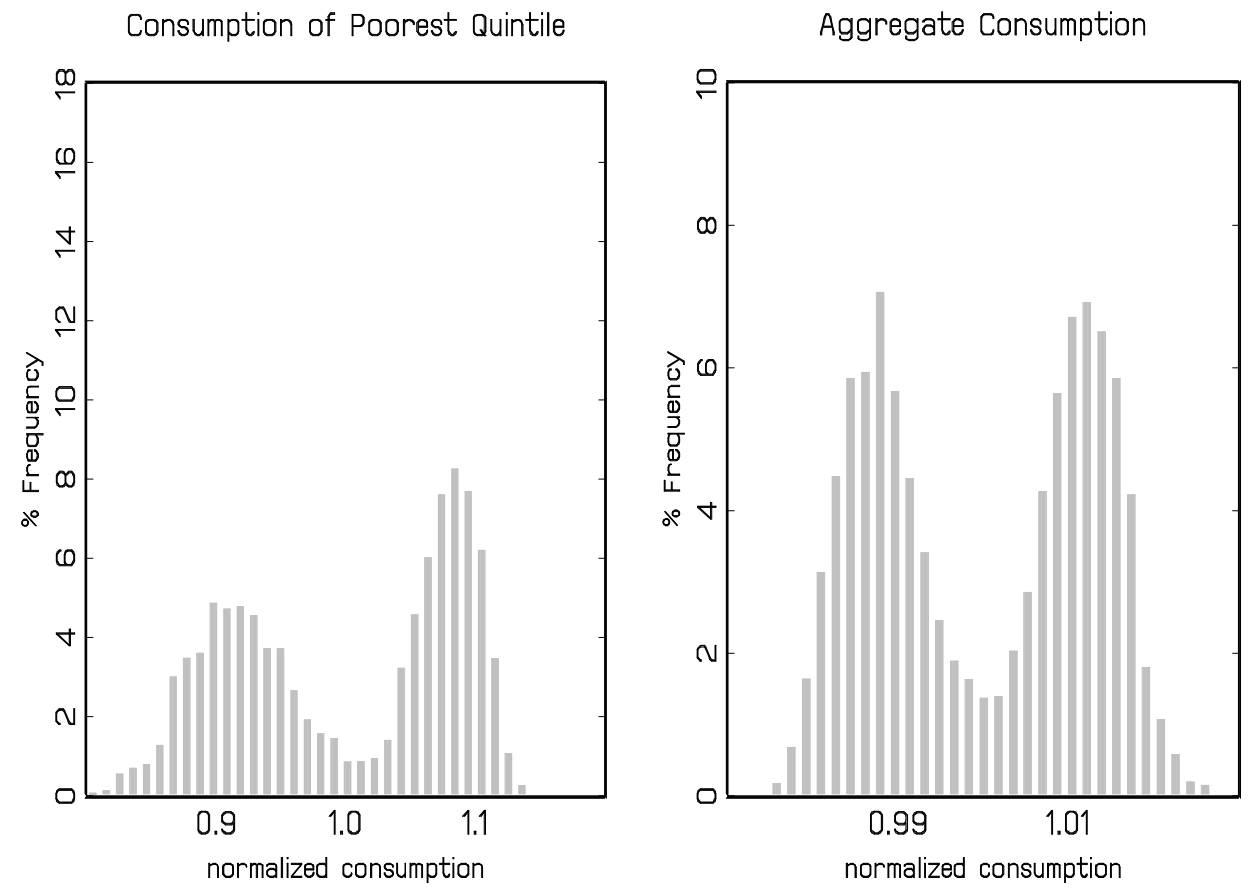

Consumption of Richest Quintile
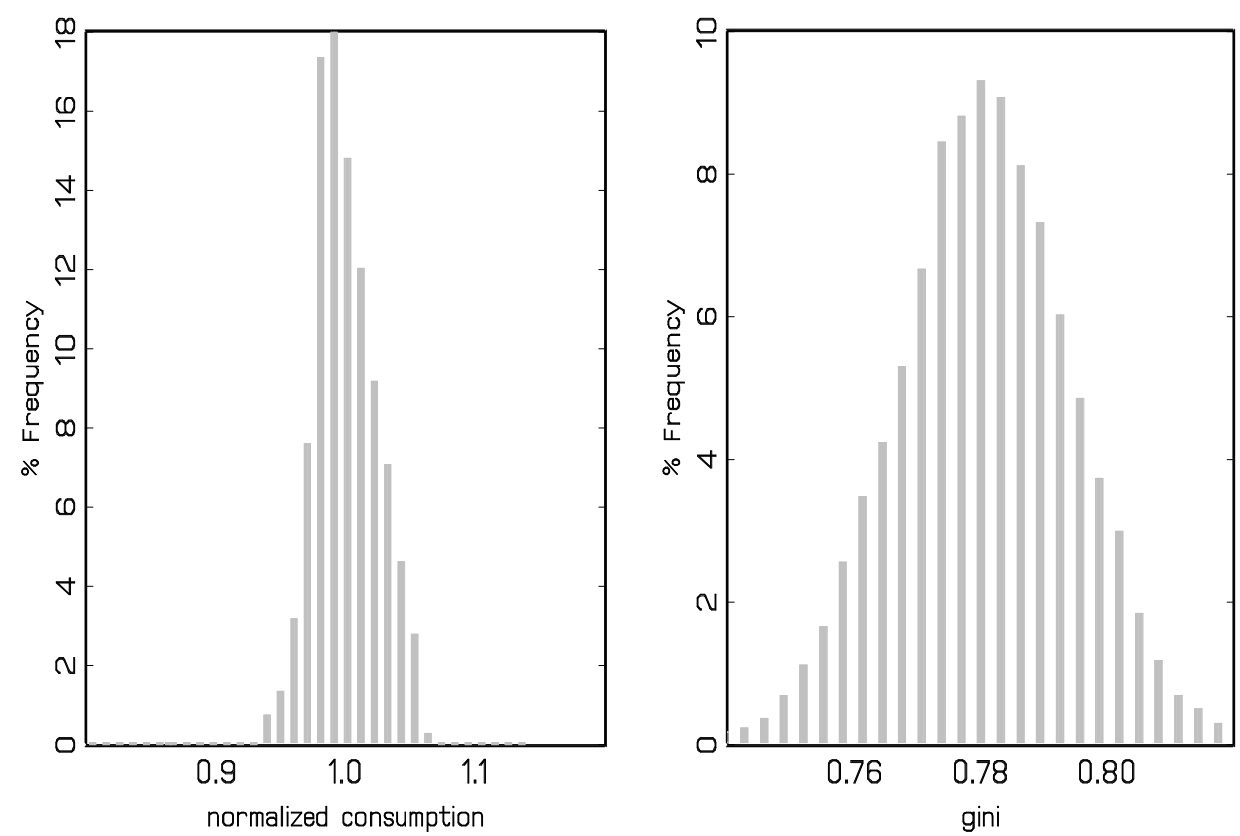
Figure 4: Tax Increase in Benchmark Experiment [1]

TAX REVENUE

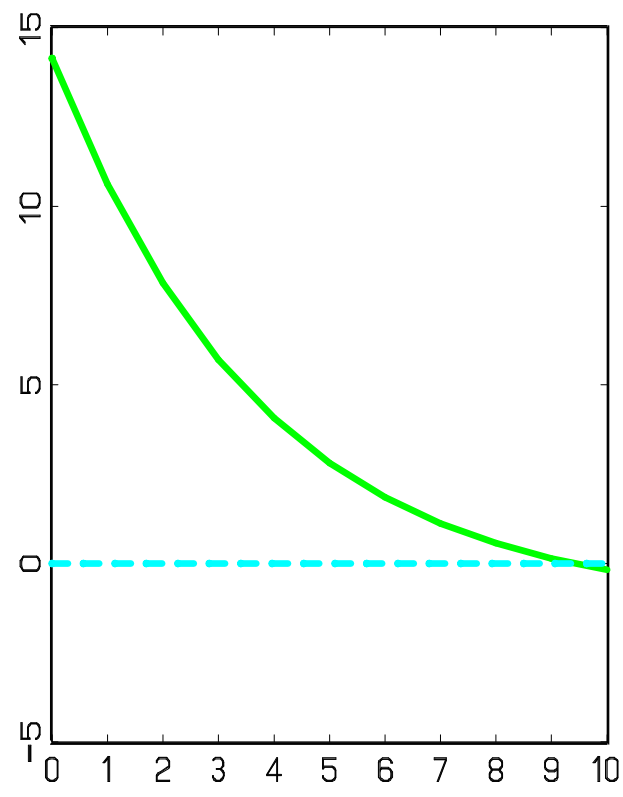

AGG INV

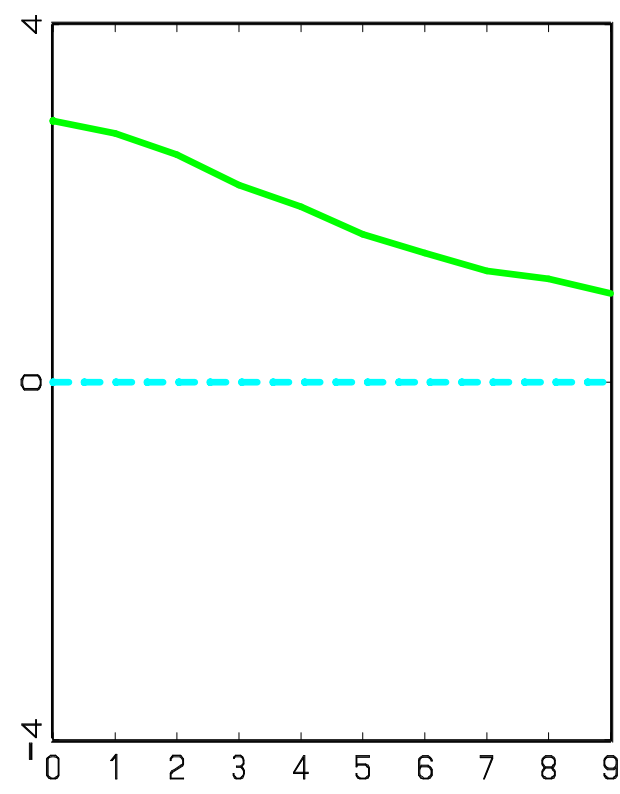

GOV DEBT

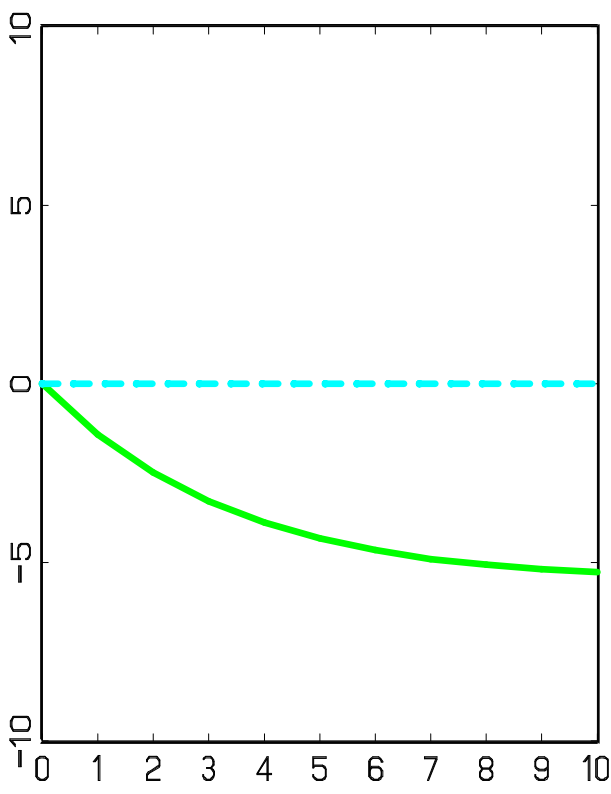

AGG CON

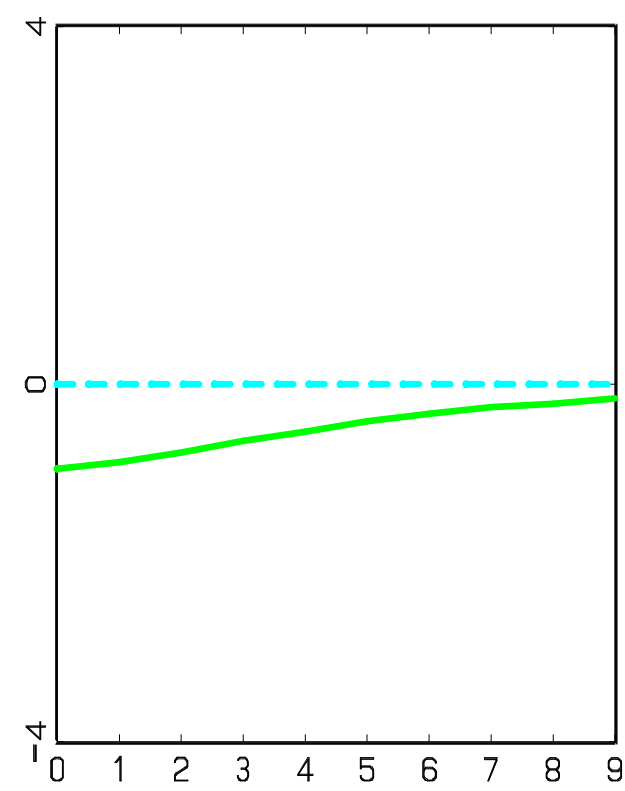


Figure 5: Tax Increase in Benchmark Experiment [2]

CON POOREST QUINTILE

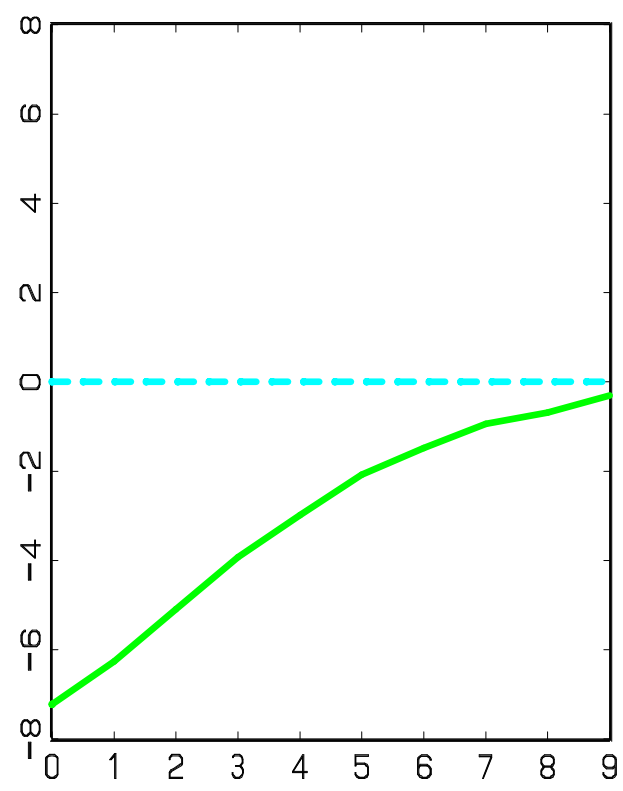

WEALTH GINI

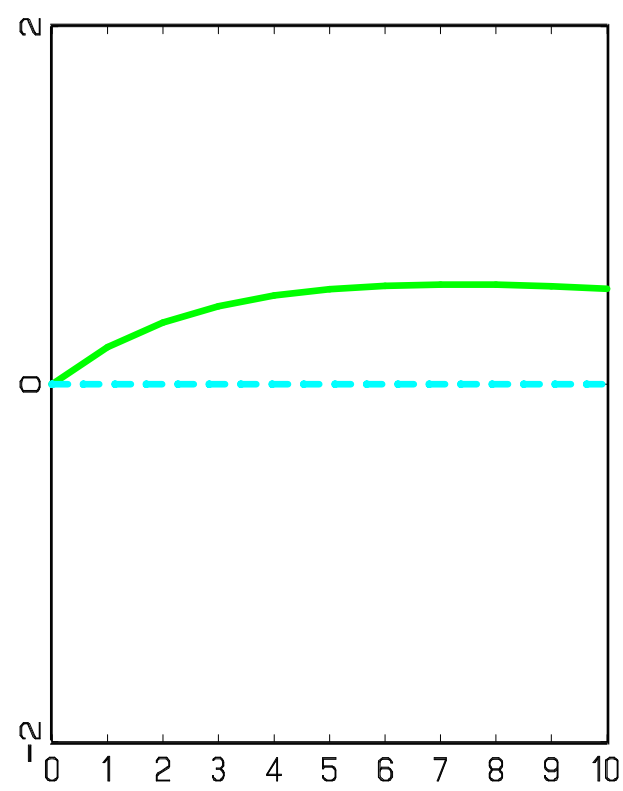

CON RICHEST QUINTILE

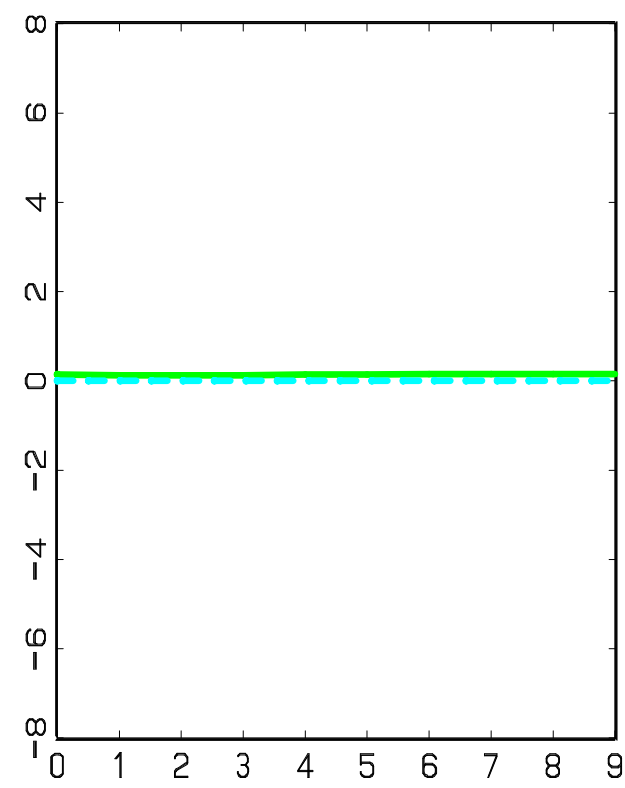

$R$ [ANNUALIZED]

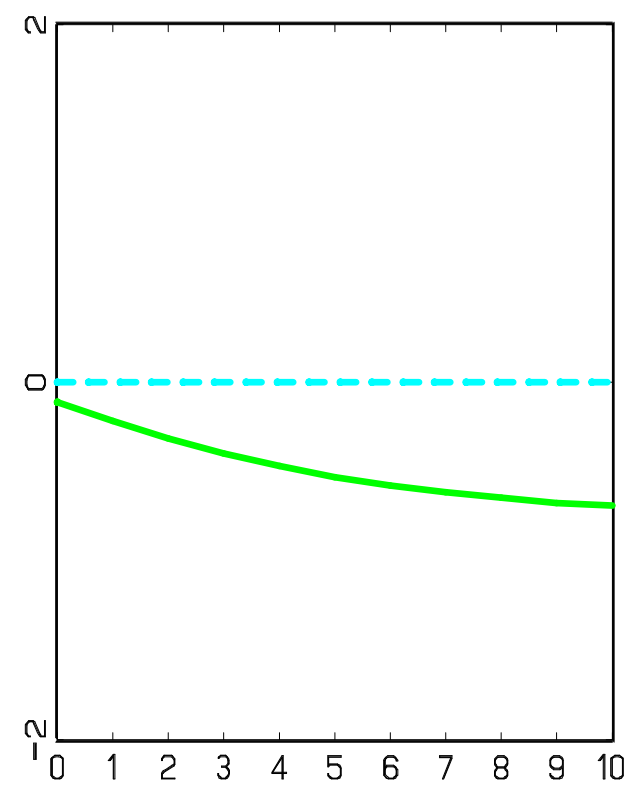


Figure 6: Change in Consumption by Asset Holding Quintile

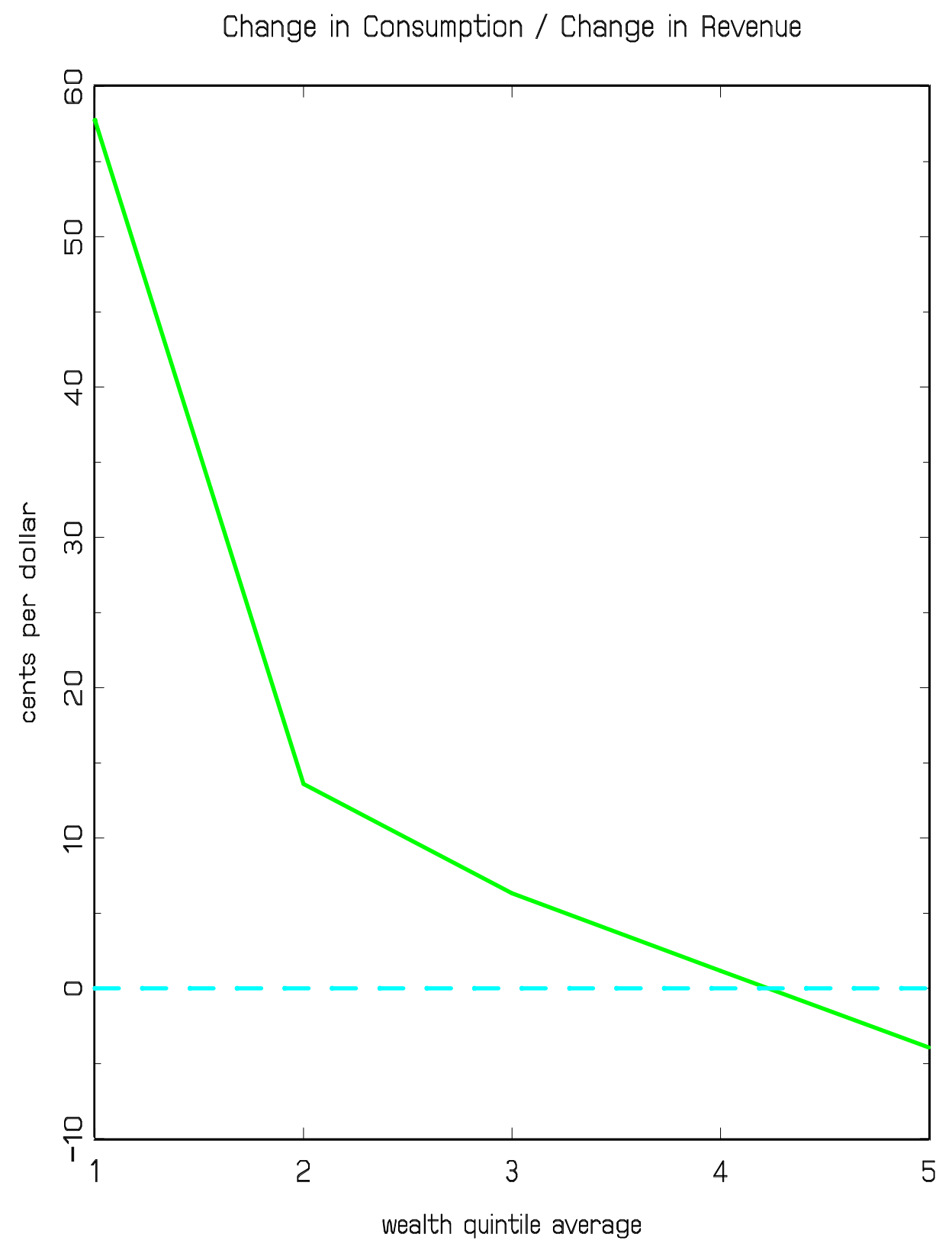


Figure 7: Tax Cut in Low Debt Experiment

TAX REVENUE
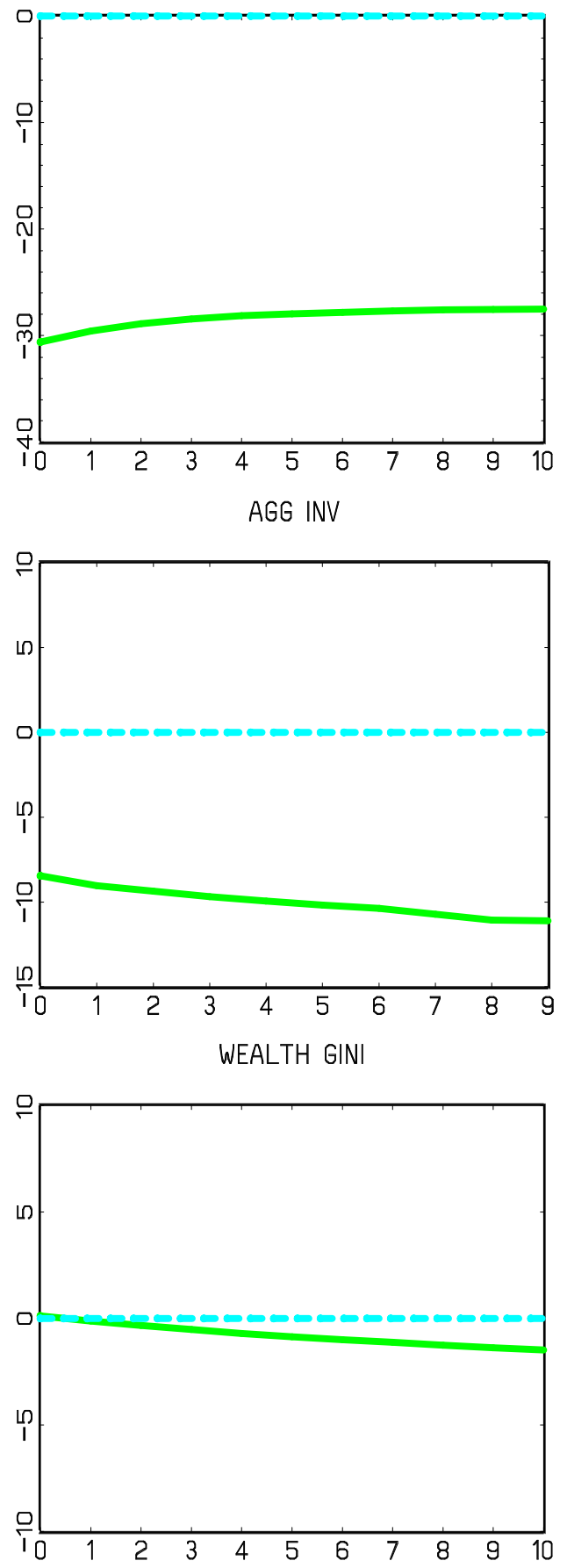

GOV DEBT
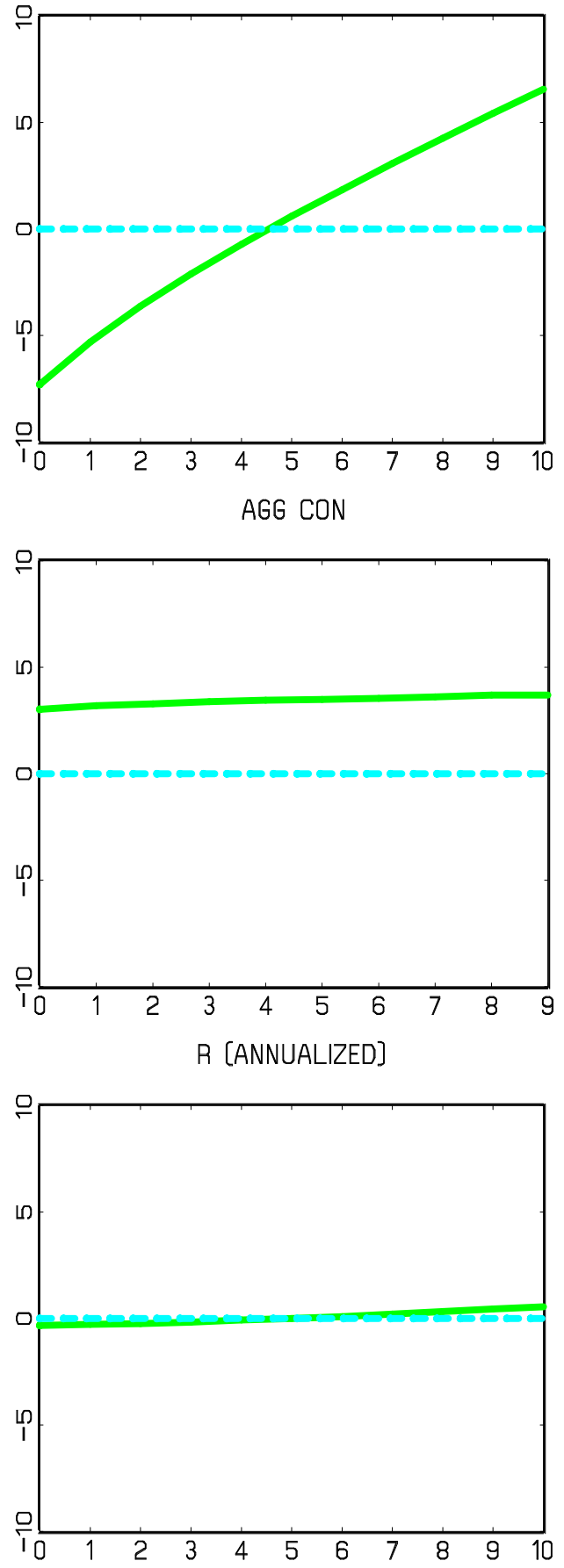
Figure 8: Tax Increase in High Debt Experiment
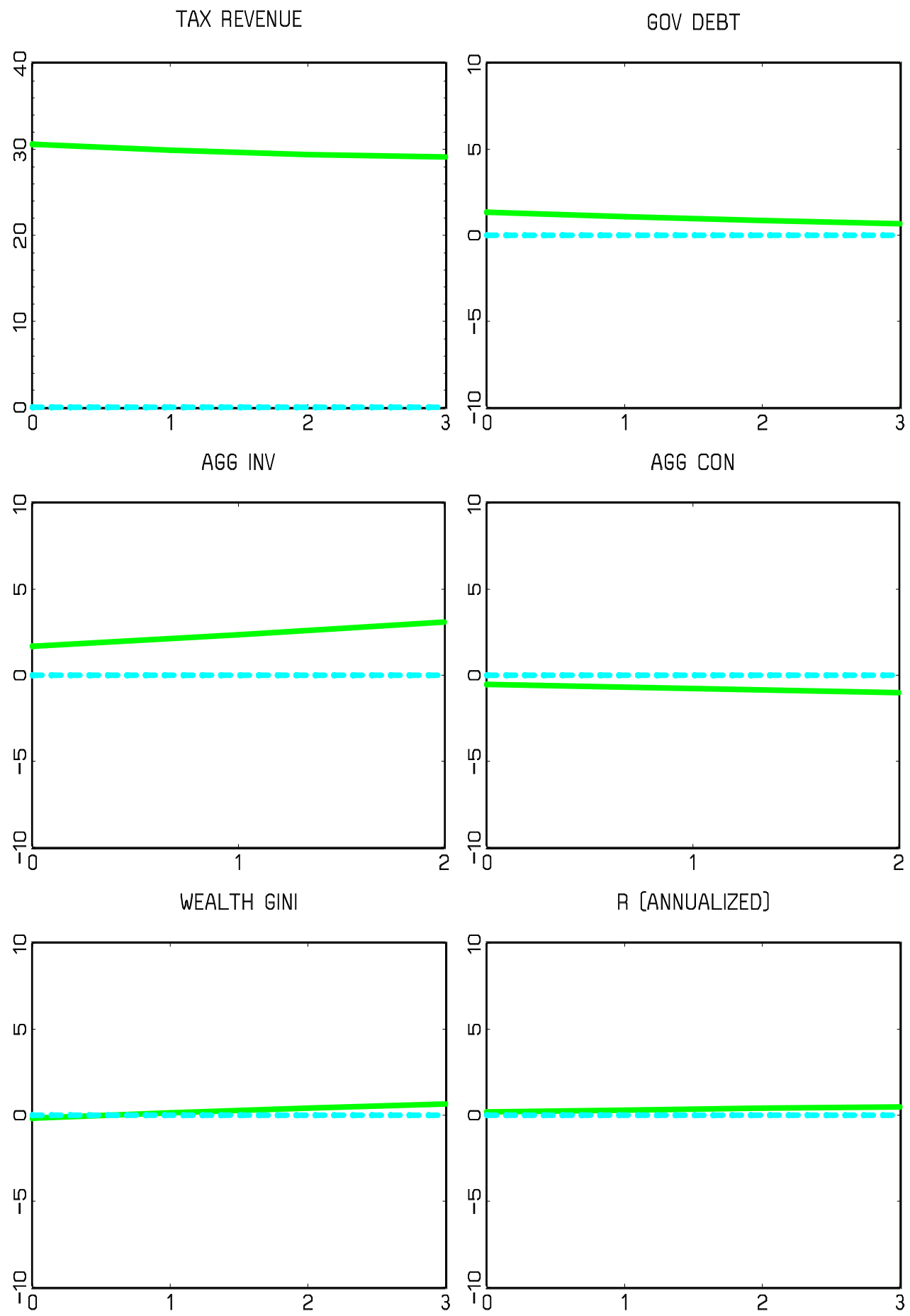
Figure 9: Forecast Errors

1 Period Forecast Errors for $\mathrm{K}$

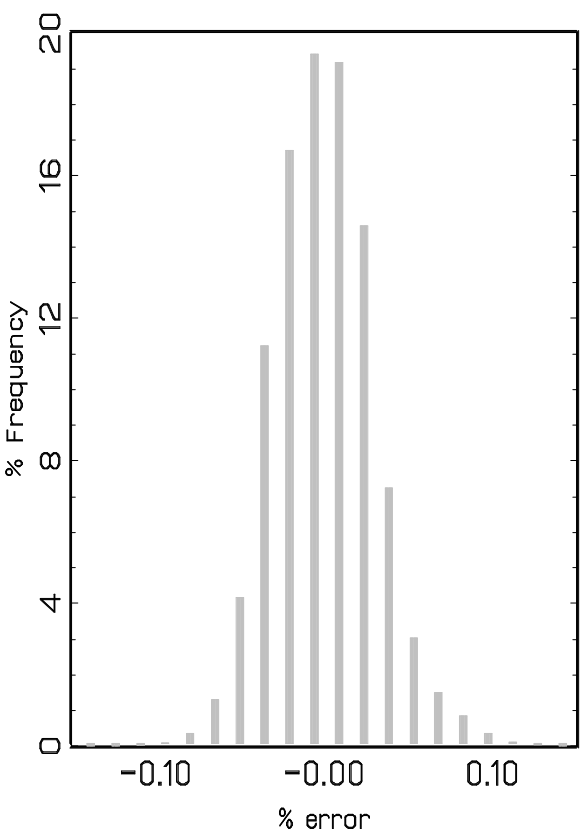

1 Period Forecast Errors for $\mathrm{R}$

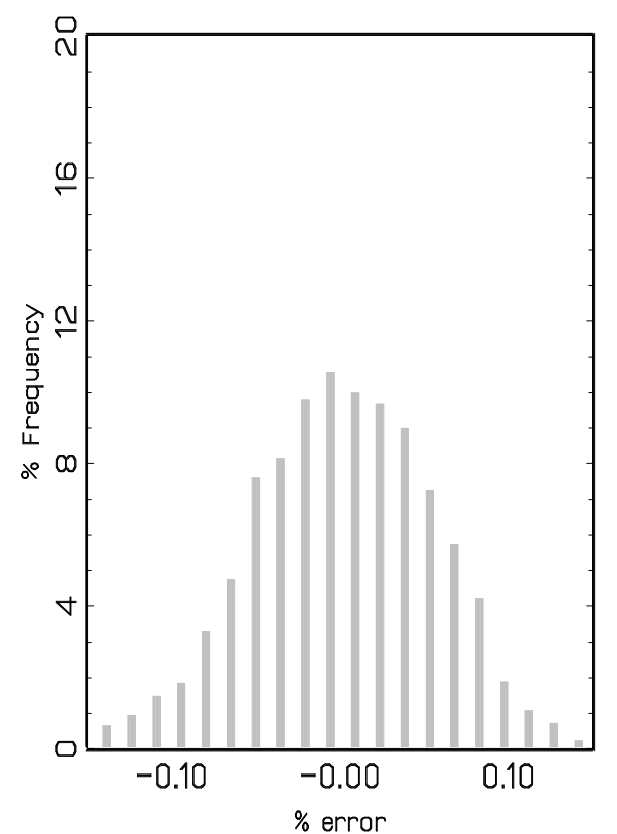

100 Period Errors for $\mathrm{K}$

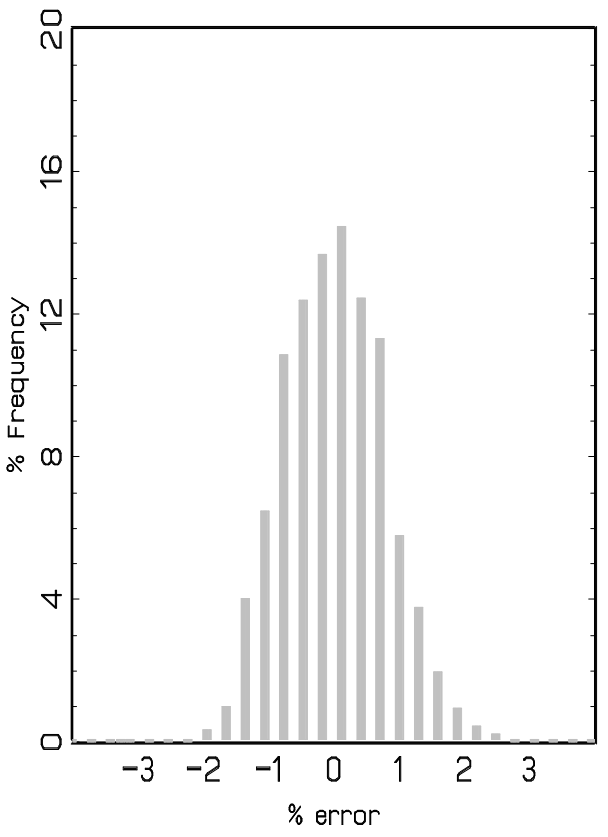

100 Period Errors for $\mathrm{R}$

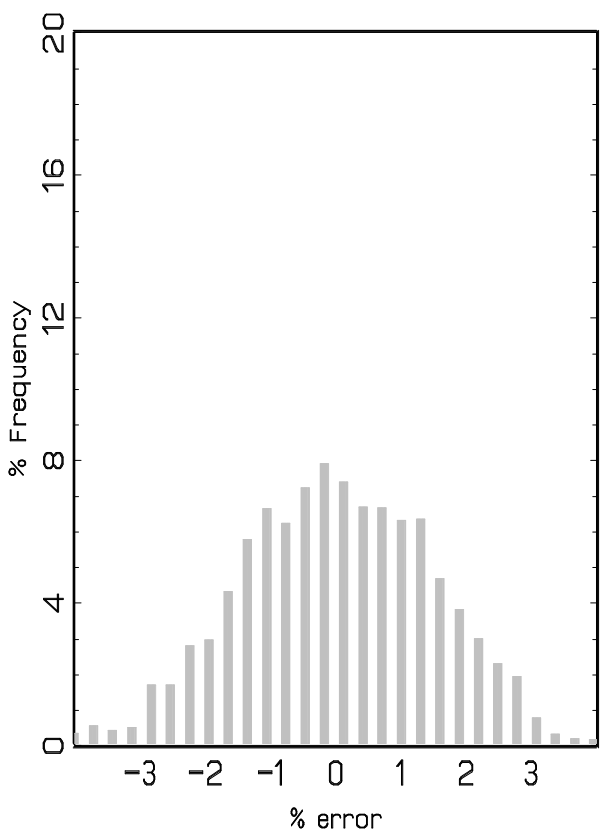


Figure 10: Savings Decision Rules

[agg. capital $=8.78$, agg. debt $=2.35$, mean household wealth $=11.13$ ]

Low Productivity, Low Beta

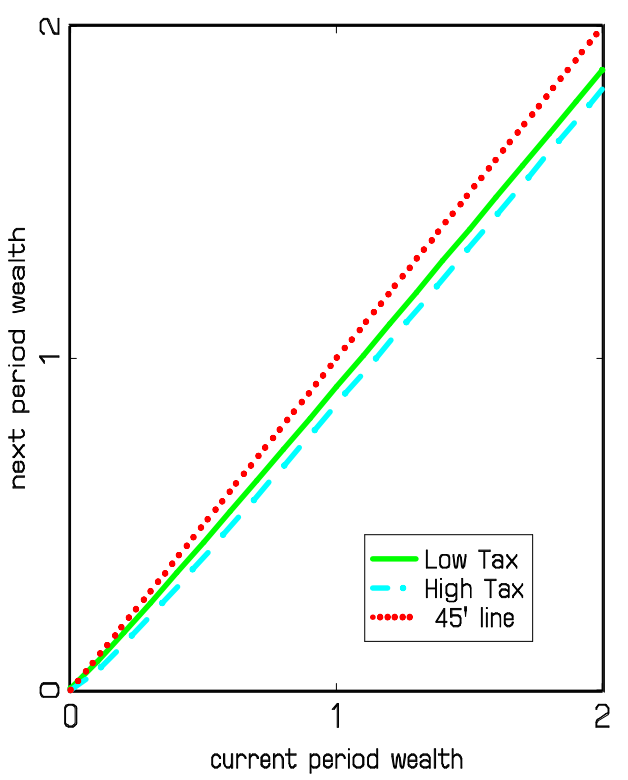

High Productivity, Low Beta

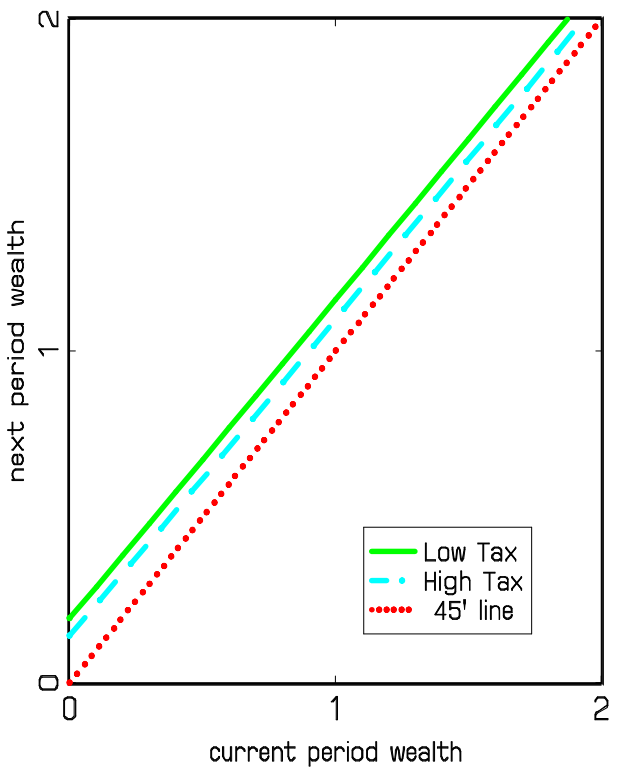

Low Productivity, High Beta

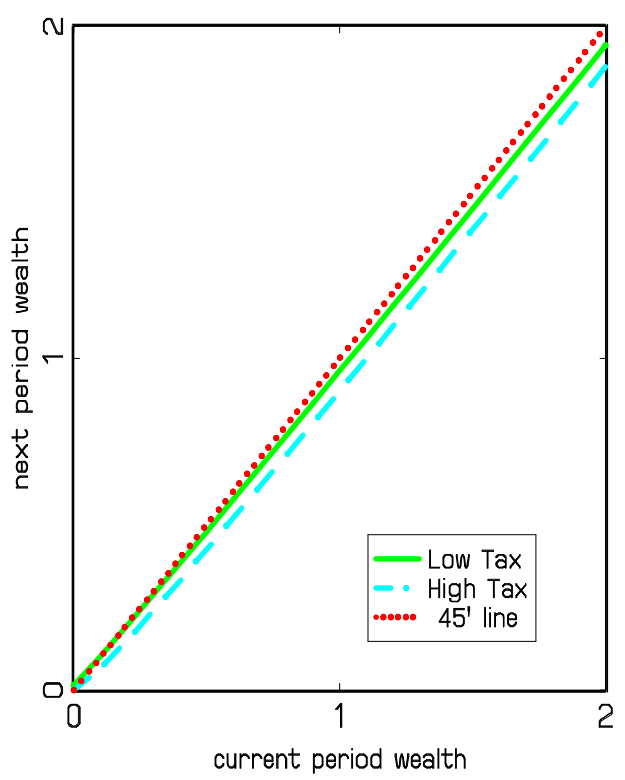

High Productivity, High Beta

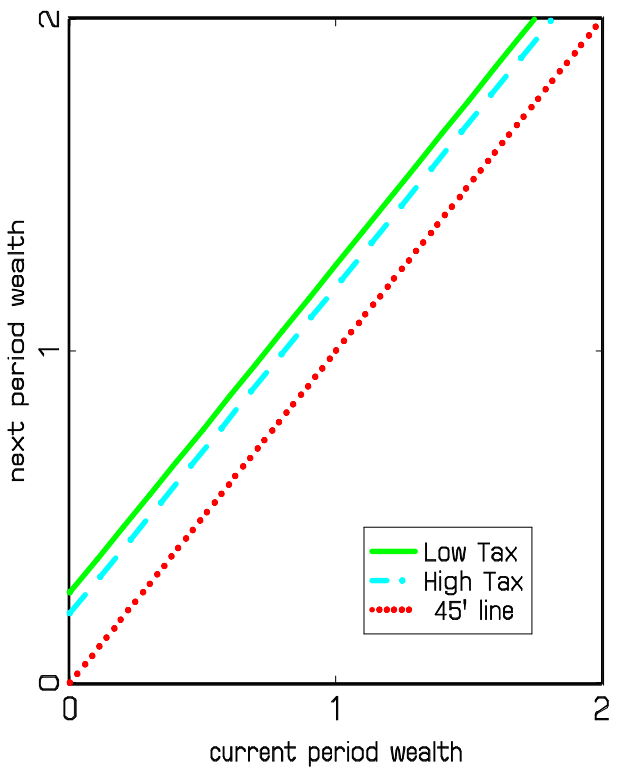


Figure 11: Consumption Decision Rules

[agg. capital $=8.78$, agg. debt $=2.35$, mean household wealth $=11.13$ ]

Low Productivity, Low Beta

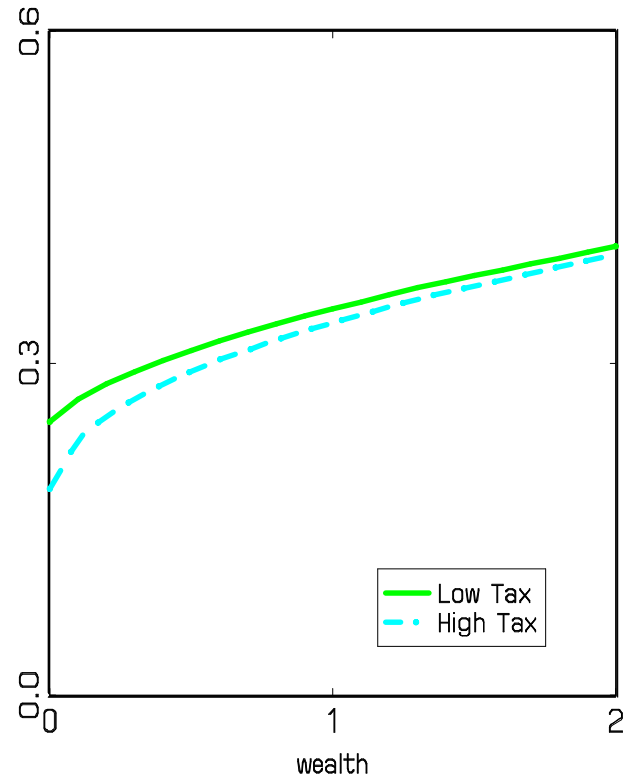

High Productivity, Low Beta

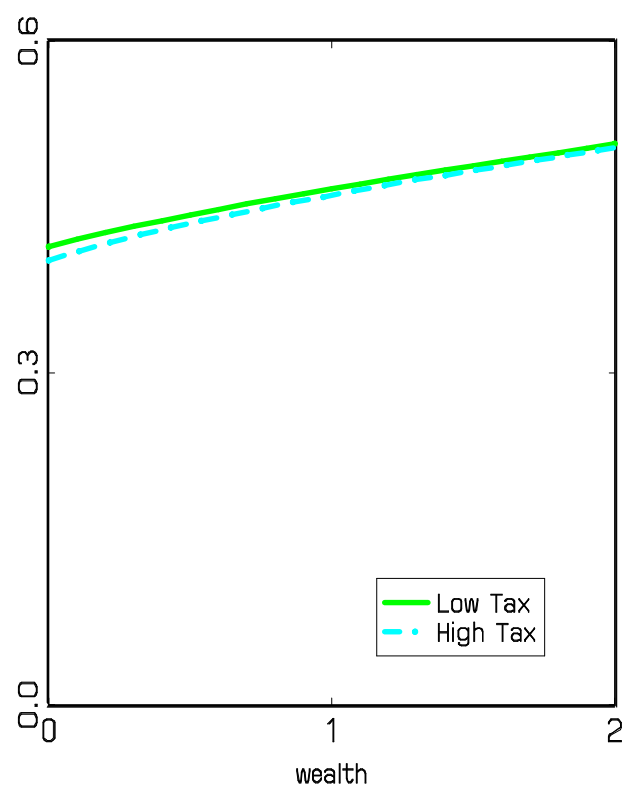

Low Productivity, High Beta

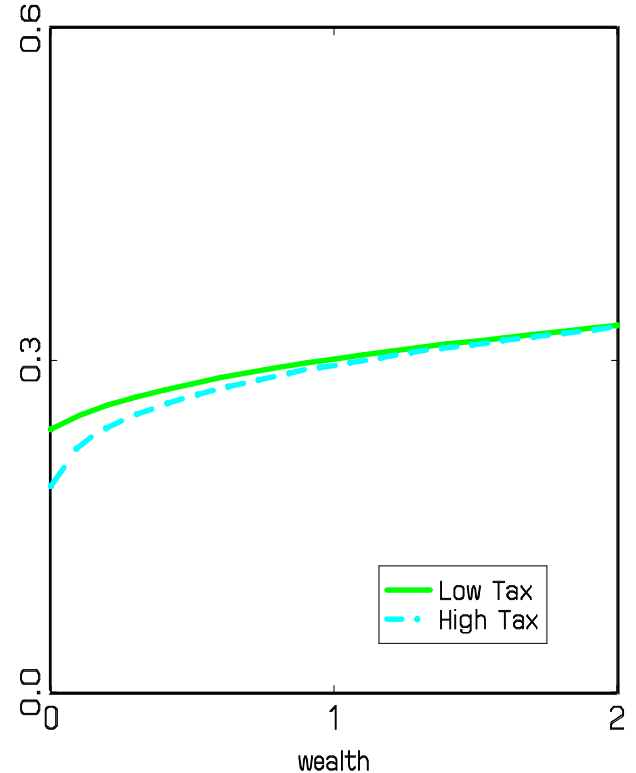

High Productivity, High Beta

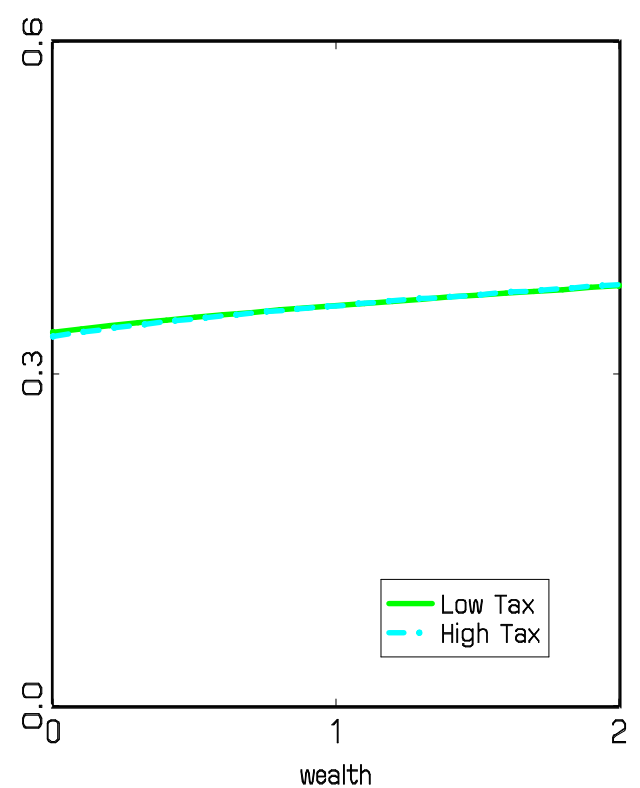

